\title{
An Update on Plant Photobiology and Implications for Cannabis Production
}

\author{
Samuel Eichhorn Bilodeau, Bo-Sen Wu, Anne-Sophie Rufyikiri, Sarah MacPherson \\ and Mark Lefsrud*
}

Department of Bioresource Engineering, McGill University, Montreal, QC, Canada

OPEN ACCESS

Edited by:

Giuseppe Mandolino,

Council for Agricultural

Research and Analysis of

Agricultural Economics, Italy

Reviewed by:

Theoharis Ouzounis,

Fluence Bioengineering, Inc.,

United States

Jason Wargent,

Massey University, New Zealand

*Correspondence:

Mark Lefsrud

mark.lefsrud@mcgill.ca

Specialty section:

This article was submitted to

Crop and Product Physiology,

a section of the journal

Frontiers in Plant Science

Received: 05 November 2018

Accepted: 25 February 2019

Published: 29 March 2019

Citation:

Eichhorn Bilodeau S, Wu B-S, Rufyikiri A-S, MacPherson S and Lefsrud M (2019) An Update on Plant

Photobiology and Implications for

Cannabis Production.

Front. Plant Sci. 10:296.

doi: 10.3389/fp/s.2019.00296
This review presents recent developments in plant photobiology and lighting systems for horticultural crops, as well as potential applications for cannabis (Cannabis sativa and C. indica) plant production. The legal and commercial production of the cannabis plant is a relatively new, rapidly growing, and highly profitable industry in Europe and North America. However, more knowledge transfer from plant studies and horticultural communities to commercial cannabis plant growers is needed. Plant photosynthesis and photomorphogenesis are influenced by light wavelength, intensity, and photoperiod via plant photoreceptors that sense light and control plant growth. Further, light properties play a critical role in plant vegetative growth and reproductive (flowering) developmental stages, as well as in biomass, secondary metabolite synthesis, and accumulation. Advantages and disadvantages of widespread greenhouse lighting systems that use high pressure sodium lamps or light emitting diode (LED) lighting are known. Some artificial plant lighting practices will require improvements for cannabis production. By manipulating LED light spectra and stimulating specific plant photoreceptors, it may be possible to minimize operation costs while maximizing cannabis biomass and cannabinoid yield, including tetrahydrocannabinol (or $\Delta^{9}$-tetrahydrocannabinol) and cannabidiol for medicinal and recreational purposes. The basics of plant photobiology (photosynthesis and photomorphogenesis) and electrical lighting systems are discussed, with an emphasis on how the light spectrum and lighting strategies could influence cannabis production and secondary compound accumulation.

Keywords: cannabis, Cannabis sativa, HPS, LEDs, light, photobiology, photomorphology, photosynthesis

\section{INTRODUCTION}

The legal status of cannabis production is shifting, causing a rapidly expanding market in both North America and Europe. Canada has become the second country in the world to legalize the use of both medicinal and recreational cannabis (Dyer, 2018). Such full legalization allows industry and researchers to work together to explore the uncharted science of this once-forbidden plant. Although cannabis (Cannabis sativa ssp.) has been harvested for food (seeds), fiber (stems), and medicine (buds) throughout most of human history (Mercuri et al., 2002; 
Clarke and Merlin, 2013), its listing as an illegal drug to date has left little published scientific literature.

Commercial cannabis production typically occurs indoors and requires environmental controls such as humidity and lighting for both vegetative growth and budding (flowering) developmental stages (Hillig, 2005). During the vegetative growth stage, high light intensity is needed to maximize cannabis growth and proper photoperiodicity control is necessary to initiate budding (Arnold, 2013). Growing cannabis plants solely with indoor lighting allows a continuous and uniform cannabinoid yield for high-quality products, but it requires high-energy inputs. As such, indoor cannabis production has been classified as one of the most energy-intensive industries in the US (Warren, 2015). In this regard, the selection of electrical lighting systems and light spectra are of utmost importance, as they determine operation costs and consequent product pricing.

In the general horticultural industry, growers use different light spectra and intensities to influence plant morphology, secondary metabolism, and flowering (Lefsrud et al., 2008; Kohyama et al., 2014; Wang et al., 2016). However, commercial growers in the cannabis industry are still referring to unreliable information, given the lack of peer-reviewed reports on cannabis production. Exceptionally, it has been reported that reducing the photoperiod to approximately $12 \mathrm{~h}$ is a common practice in the cannabis production industry to initiate flowering (Chandra et al., 2017). For other commonly grown flowering plants in the horticultural industry, flowering is initiated via night interruption (Yamada et al., 2008; Blanchard and Runkle, 2010; Park et al., 2016). Both methods initiate flowering; however, reducing photoperiod potentially leads to plant yield reduction.

With decades of research committed to understanding the impact of narrow light spectra on plant growth, the basis of wavelength effect on photosynthesis and photomorphogenesis for greenhouse crops has been well investigated (Massa et al., 2008; Bugbee, 2016; Bantis et al., 2018). Until now, our knowledge of cannabis production has stemmed from experiments performed when growing cannabis was illegal (Vanhove et al., 2011). Current findings in plant photobiology and lighting control will provide the information needed by horticultural scientists to establish optimal cannabis production protocols and to maximize cannabinoid yields. To this end, this review focuses on recent developments and our current understanding of photosynthesis and photomorphogenesis in greenhouse crops, with the latest reports on cannabis production in order to adequately inform the industry on the importance of lighting control for cannabis growth and cannabinoid production. A brief overview of the cannabis profile is provided, and three main topics are explored: (1) light, photosynthesis, and photosynthetically active radiation (PAR); (2) photomorphogenesis, plant photoreceptors, and secondary plant metabolites; and (3) electrical lighting systems.

Abbreviations: CBD: cannabidiol, FR: far red, HPS: high pressure sodium, IR: infrared radiation, LED: light emitting diode, PAR: photosynthetically active radiation, PCET: proton-coupled electron transfer, PPFD: photosynthetic photon flux density, THC (or $\Delta 9$ : THC): tetrahydrocannabinol ( $\Delta^{9}$-tetrahydrocannabinol), UV: ultraviolet.

\section{CANNABIS PROFILE}

The cannabis plant is the one of the oldest plant sources for food, medicinal, or ritual use (Kriese et al., 2004; Chandra et al., 2017). Today, cannabis is often referred to as marijuana, a term used to describe a female cannabis plant that produces flower buds, as opposed to hemp, which is grown for several industrial applications. Throughout this review, use of the term "cannabis" will refer to the female cannabis (C. sativa) plant with high psychoactive properties. Cannabis plants synthesize and accumulate 60-85 different psychoactive cannabinoids in their budding structures, and these are directly associated with cannabis consumption (El-Alfy et al., 2010). The most abundantly produced cannabinoids in cannabis plants are tetrahydrocannabinol [THC; or $\Delta^{9}$-tetrahydrocannabinol $\left(\Delta^{9-} \mathrm{THC}\right)$, cannabidiol (CBD), and the primary product of THC-degradation, cannabinol (Benson et al., 1999)]. The most psychoactive cannabinoid is THC, and its pharmacology has been well studied (El-Alfy et al., 2010). Over the last few years, CBD has drawn significant attention since its reported therapeutic potential as a treatment for intractable pediatric epilepsy (Friedman and Devinsky, 2015).

The Cannabis genus is commonly conceived as only constituting a single species. However, C. sativa L. may be divided into three sub-species: C. sativa ssp. sativa, C. sativa ssp. indica, and C. sativa ssp. ruderalis. The first two species, often referred to as "Sativa" and "Indica", are the main cannabis plant species of recreational and medicinal interest (McPartland, 2017). They have distinct yet opposing THC and $\mathrm{CBD}$ ratios; C. sativa ssp. indica typically possesses a high THC to CBD ratio (Fischedick et al., 2010), whereas the reverse is known for C. sativa ssp. sativa. In today's marketplace, however, these distinctions are almost meaningless as new strains have been created from crossbreeding. C. ruderalis is the least known subspecies, and it is not commercially produced because of low plant yields (Fischedick et al., 2010).

\section{LIGHT, PHOTOSYNTHESIS, AND PHOTOSYNTHETICALLY ACTIVE RADIATION (PAR)}

Light is one of the most important environmental parameters that impacts plant growth and development. It exerts a vast range of effects on photosynthetic activity and photomorphogenic responses throughout the plant's life (Pocock, 2015; Naznin et al., 2016; Ouzounis et al., 2016). Close to half of the sun's total radiation emission reaching the Earth's surface is visible light, ranging from 400 to $740 \mathrm{~nm}$ wavelengths (Both et al., 2015). Visible light is flanked by shorter wavelengths and invisible ultraviolet (UV) electromagnetic radiation (10-400 nm) and by infrared radiation (IR; 700-1 mm); this roughly constitutes the remaining half of the solar radiation incident on the Earth's surface (Cooper and Hausman, 2004). These three wavelength regions of the electromagnetic spectrum are the most significant with respect to biological systems (Mishra, 2004). Visible light includes violet $(\sim 400-450 \mathrm{~nm})$, blue $(\sim 450-520 \mathrm{~nm})$, green $(\sim 520-560 \mathrm{~nm})$, yellow $(\sim 560-600 \mathrm{~nm})$, orange $(\sim 600-625 \mathrm{~nm})$, red $(\sim 625-700 \mathrm{~nm})$, 
and far-red (FR; > $700 \mathrm{~nm}$ ). The most important part of the light spectrum for plants, PAR $(400-700 \mathrm{~nm})$, falls within the visible light range (McCree, 1972a,b; van Iersel, 2017).

\section{The Basis of Photosynthesis}

Photosynthesis plays a critical role in plant growth, as there is a close correlation between plant productivity and their photosynthetic rates in a given environment (Zelitch, 1975). Photosynthesis defines the complex set of reactions by which plant and phototrophic cells harvest, transfer, and store light energy as chemical potential in the carbon bonds of carbohydrates (Cooper and Hausman, 2004). Photosynthesis occurs within the chloroplast, a chlorophyll-bearing plastid organelle dedicated to energy production (Cooper and Hausman, 2004; Mishra, 2004). Chloroplasts are mostly found in the cytoplasm of palisade and spongy mesophyll cells located between the bounding epidermal layers of leaves (Mishra, 2004). The energy-generating, photooxidation-reduction reactions of photosynthesis occur within the third, internal thylakoid membrane system of the chloroplast; it forms networks of flattened thylakoid disks, often stacked in grana (Cooper and Hausman, 2004). Embedded in the thylakoid membrane are five-membrane protein complexes that serve in electron transport and the concomitant synthesis of the energy carrier molecules NADPH and ATP, fueling carbohydrate synthesis. Prominent among these are the two main photosynthetic light reaction centers, membrane protein photosystem I and II complexes (PSI and PSII), named after the order of their discovery yet counterintuitive to their evolution in nature (Cooper and Hausman, 2004).

The aforementioned photosystems contain arrays of associated chlorophyll and carotenoid antenna pigments, molecules involved in harvesting light energy for photosynthesis, organized in such a way as to maximize light energy capture and transfer. Plant pigments have specific wavelength absorbance patterns known as the absorbance spectrum (Figure 1). Chlorophylls $a$ and $b$ (Chl $a$ and $b$ ) absorb wavelengths of light strongly in the red and blue regions, with less absorbance occurring in the green wavelengths. In acetone, Chl $a$ exhibits peak absorbance at 430 and $663 \mathrm{~nm}$, while $\mathrm{Chl} b$ peaks at 453 and $642 \mathrm{~nm}$. The pigments $\beta$-carotene and lutein in acetone absorb strongly in the blue region of light with a maximum peak occurring at 454 and $448 \mathrm{~nm}$, respectively (Hopkins and Hüner, 1995; Taiz and Zeiger, 2002). These pigments have local absorbance peaks, while $\beta$-carotene has a second absorbance peak at $477 \mathrm{~nm}$, and lutein has two local absorbance peaks at 422 and $474 \mathrm{~nm}$. However, it is important to note that peak absorbance can shift up to $38 \mathrm{~nm}$ and is dependent on the specific environment surrounding the chloroplasts (Heber and Shuvalov, 2005).

\section{Photosynthetically Active Radiation (PAR) and Standard Units for Plant Lighting}

Understanding the spectral quality of photosynthesis is critical when selecting a lighting system with proper light quality and quantity for any indoor plant cultivation. Our current understanding of the spectral quality of photosynthesis is mainly based on McCree's findings in the 1970s (McCree, 1972a). The action spectrum of plant leaves was described as the span of wavelengths from approximately $400-700 \mathrm{~nm}$, over which plants absorb and effectively use radiant light energy for photosynthesis (McCree, 1972a). This brought some definition to what is now

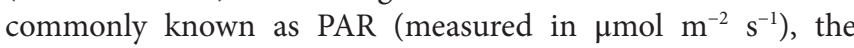

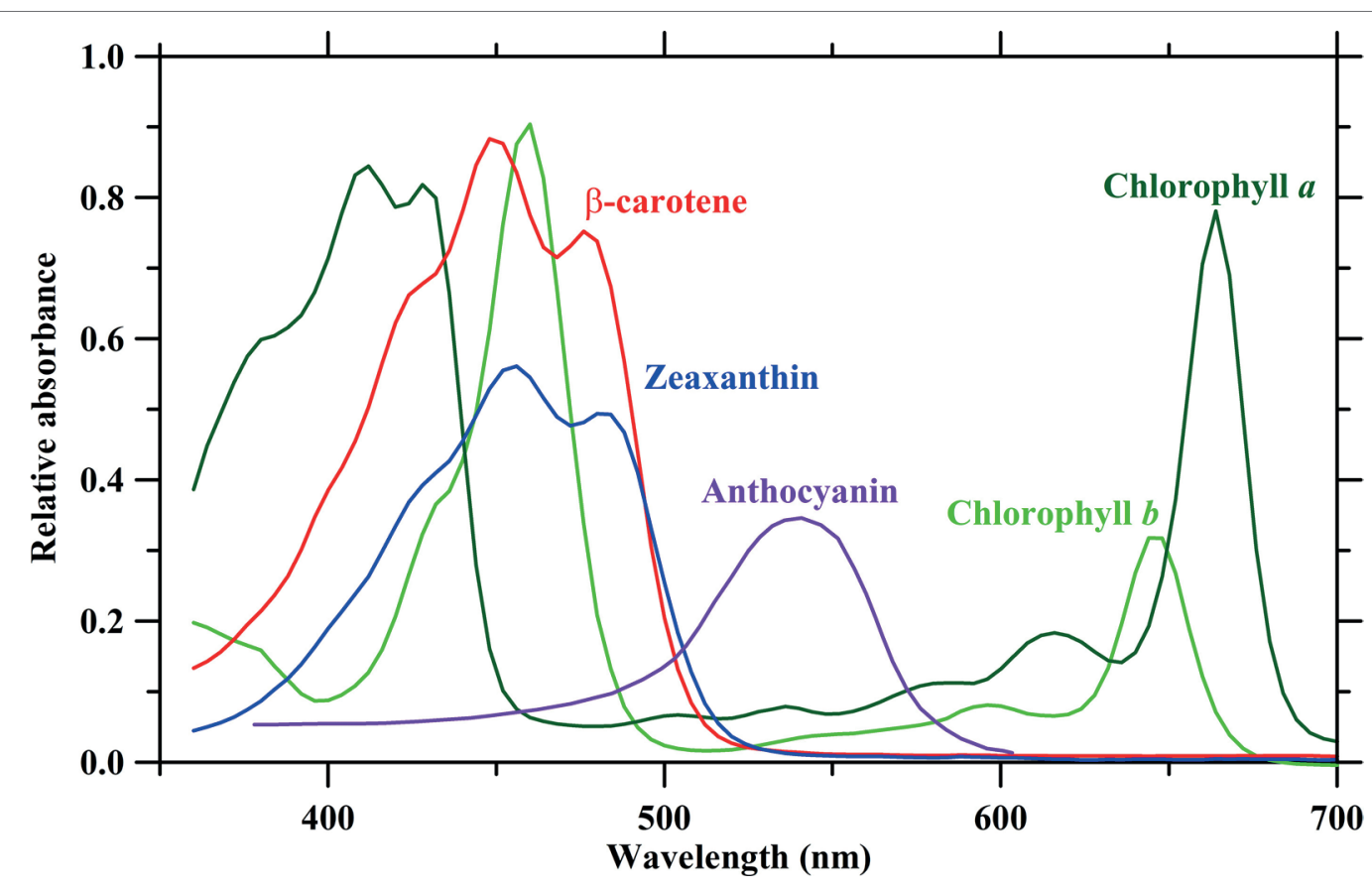

FIGURE 1 | Absorbance spectra of plant photosynthetic pigments in acetone. Absorbance data are derived from Avital et al. (2006), Kobayashi et al. (2013), Heddad et al. (2006), and Taiz and Zeiger (2002). 
measure of that relates the intensity and rate of radiant light energy per surface area emitted by a light source from within the action spectrum of plants. To achieve this, the photosynthetic spectral quantum yield or the $\mathrm{CO}_{2}$ consumed by plant leaves per mole of photons absorbed was determined for 22 crop plant species by correlating the monochromatic light irradiance intensity $\left(\mathrm{W} \mathrm{m} \mathrm{m}^{-2}\right.$ ) required to obtain a certain rate of photosynthesis in leaf fragments to their absorption spectrum, measured in an integrating sphere with a spectrophotometer. The assay covered the wavelength range from 350 to $750 \mathrm{~nm}$, in $25 \mathrm{~nm}$ waveband increments, and photosynthesis was measured based on the $\mathrm{CO}_{2}$ uptake rate, measured with an infrared gas analyzer based on $\mathrm{CO}_{2}$ differentials under dark light versus the tested wavelength band of light. Two major, distinct peaks at 440 and $620 \mathrm{~nm}$ were observed, followed by a secondary peak at $670 \mathrm{~nm}$. To this end, McCree's experiments first described a plant's PAR curve, a term that defines a plant's light action spectrum and the wavelengths used most efficiently for glucose biosynthesis and the storage of free chemical energy (McCree, 1972b; Young, 1991).

McCree (1972b) determined that quantifying PAR in quantum or photon flux units based on moles of photons would yield results that more closely correlated to the actual photosynthetic rate, since photosynthesis is a quantum photochemical process, with one carbon fixed and one molecule of oxygen evolved per roughly 10 photons (quanta) of light absorbed. Both units of measurement, radiant flux density $\left(\mathrm{W} \mathrm{m} \mathrm{m}^{-2}\right.$ ) and photon flux density $\left(\mu \mathrm{mol} \mathrm{m} \mathrm{m}^{-2} \mathrm{~s}^{-1}\right)$, are typically used to report plant lighting systems (McCree, 1972a; Inada, 1976; Both et al., 2015); however, plant yields are overestimated for blue light over red light when using radiant flux density, and this overestimation is smaller when light energy is measured in photon flux density (McCree, 1972b; Inada, 1976). Therefore, PAR is defined from 400 to $700 \mathrm{~nm}$ in quantum units of photosynthetic photon flux density (PPFD, $\mu \mathrm{mol} \mathrm{m} \mathrm{m}^{-2} \mathrm{~s}^{-1}$ ) (McCree, 1972b; Inada, 1976; van Iersel, 2017). PPFD is broadly considered as the available estimate of potential photosynthetic flux, since the two are positively correlated. PAR is determined by integrating PPFD values within the limits of the plant action spectrum for photosynthesis (Mccree, 1971, 1972b). Based on McCree's findings on plant action spectrum, the PAR spectrum is used to integrate photon flux values, and PPFD gives an instantaneous estimate of potential photosynthetic activity with regard to measured light source emissions (Sager and Giger, 1980; Sager et al., 1982).

Although McCree (1972a,b) proved that the use of PPFD is necessary when quantifying photosynthetic productivity over four decades ago, other photometric units of light such as lumens, lux, or foot-candles are still employed. These photometric units are based on the eye's response to brightness, where human eyes are more sensitive to green light than red or blue light. Moreover, light below $400 \mathrm{~nm}$ and above $700 \mathrm{~nm}$ induces photosynthetic activity, which was not previously considered in PAR (McCree, 1972a; Inada, 1976). This led to the use of yield photon flux. Yield photon flux weighs photosynthetic activity from 360 to $760 \mathrm{~nm}$ based on McCree's quantum yield curve, under the assumption that the curve remains true with different light conditions (Sager et al., 1988; Barnes et al., 1993). Importantly, all spectral quality studies were conducted under low light intensity $\left(<150 \mu \mathrm{mol} \mathrm{m} \mathrm{m}^{-2} \mathrm{~s}^{-1}\right)$. Whether the curve keeps its infamous form under higher light intensities or can be applied to other plants remains to be determined (Lefsrud et al., 2008). In the case of cannabis plants, most studies have been conducted under light intensities ranging from 300 to $2000 \mu \mathrm{mol} \mathrm{m} \mathrm{m}^{-2} \mathrm{~s}^{-1}$; this is higher than what is typically used for greenhouse crops and all spectral quality studies (McCree, 1972a; Inada, 1976; Chandra et al., 2008; Chandra et al., 2015). In this scenario, the spectral quality of photosynthesis for cannabis plants is required to optimize growth.

\section{Light Compensation and Saturation Points}

Increased PPFD increases with plant growth and photosynthetic rate, and this linear increase occurs between the light compensation point and the light saturation point. The light compensation point is the point at which the photosynthetic activity of the plant equals its respiration activity, and the resulting $\mathrm{CO}_{2}$ release from respiration is equivalent to that used during photosynthesis. The light compensation point is used as a base to select an appropriate light intensity. If light intensity is below the light compensation point, there is a net loss of sugars (Noodén and Schneider, 2004). For broad spectrum light, Erwin and Gesick (2017) reported that light compensation points were 25,13 , and $73 \mu \mathrm{mol} \mathrm{m} \mathrm{m}^{-2} \mathrm{~s}^{-1}$ for chard, kale, and spinach, respectively.

The light saturation point is the light intensity at which the photosynthetic rate reaches its maximum, where more light has no or a negative effect on photosynthesis. Understanding the light saturation point in plants provides lighting engineers with an opportunity to provide optimal light intensities that will maximize plant growth. Light saturation points have been investigated for many greenhouse crops, including kale, spinach, and Swiss chard (Boese and Huner, 1990; Yamori et al., 2005; Dahal et al., 2012; Ruhil et al., 2015). A study using 470 and $655 \mathrm{~nm}$ LEDs reported that the light saturation points for kale and chard ranged between 884 and $978 \mu \mathrm{mol} \mathrm{m} \mathrm{m}^{-2} \mathrm{~s}^{-1}$ and at $1238 \mu \mathrm{mol} \mathrm{m} \mathrm{m}^{-2} \mathrm{~s}^{-1}$ for spinach (Erwin and Gesick, 2017). The light saturation point for cannabis has not yet been determined, but its net photosynthetic rates at different temperatures $\left(25-40^{\circ} \mathrm{C}\right)$ and intensities (up to $2,000 \mu \mathrm{mol} \mathrm{m}{ }^{-2} \mathrm{~s}^{-1}$ ) were reported (Chandra et al., 2008; Chandra et al., 2015). In these studies, no decline in photosynthesis rate was observed at the highest intensity used; however, net photosynthetic rates at $30^{\circ} \mathrm{C}$ decreased by $\sim 20 \%$ from 1,500 to $2,000 \mu \mathrm{mol} \mathrm{m} \mathrm{m}^{-2} \mathrm{~s}^{-1}$ (Chandra et al., 2008; Chandra et al., 2015).

For any given wavelength and plant, an increase in photosynthetic rate results in increased yields until reaching the light saturation point. Therefore, additional lighting results in a similar linear increase in biomass yield that is counteracted by increased operating light-related energy costs (Terashima et al., 2009). With high-intensity LED lights, a favorable and constant light intensity above the light compensation point and below the light saturation point is required but this is species-, environment-, and grower needs-dependent (Mathieu et al., 2002; van Ieperen and Trouwborst, 2007). 


\section{PHOTOMORPHOGENESIS, PLANT PHOTORECEPTORS, AND SECONDARY PLANT METABOLITES}

Light wavelength and intensity are used to quantify light in plant lighting experiments, and it is now widely accepted that both influence photosynthesis and photomorphogenesis (Olle and Viršile, 2013; Singh et al., 2015). With the McCree curve and lighting technology improvements, photomorphogenic responses with whole plant measurements have been investigated under various wavelengths and intensities of narrow spectrum light for greenhouse crops (Hoenecke et al., 1992; Kim et al., 2004a; Li and Kubota, 2009; Stutte et al., 2009; Martineau et al., 2012). In contrast to photosynthesis that is associated with growth from direct light energy, photomorphogenesis is defined as the effect of light on plant development. Several plant responses such as germination and flowering result from the mere presence of light and are not influenced greatly by its intensity (Hall et al., 2014; Kołodziejek and Patykowski, 2015). Therefore, the outcome of a plant's response under any light spectrum results from the interactive effects between photosynthesis and photomorphogenesis. These two responses are difficult to separate from each other for long-term whole plant growth. Note that plants grown with sunlight, whether in an outdoor environment or in a greenhouse with supplemental electrical lighting, still receive the broad spectrum of light and have corresponding photomorphogenic responses. Sunlight and electrical lighting systems are further discussed in Section Traditional Light Sources.

\section{Photomorphogenic Responses and Photoreceptors}

Photomorphogenesis is the light-mediated development of plants regulated by five different photoreceptors (Figure 2; Folta and Carvalho, 2015; Pocock, 2015). They mediate and modulate dozens of structural plant developments such as height, leaf size, and flowering. These changes to plant architecture affect long-term plant development and subsequent photosynthetic surfaces.

\section{Red ( 625-700 $\mathrm{nm})$ and Far-Red $(>700 \mathrm{~nm}$ ) Light}

Red light impacts photomorphogenesis, leaf nutrient content, and stem growth. It is essential for chlorophyll synthesis and for straightening the epicotyl or hypocotyl hook of dicot seedlings (McNellis and Deng, 1995; Goins et al., 1997; Poudel et al., 2008; Johkan et al., 2012). These processes are under the influence of phytochrome control. Phytochrome is sensitive to red $(\sim 650-670 \mathrm{~nm})$ light and far-red (FR) light $(\sim 705-740 \mathrm{~nm})$, and to a lesser extent, blue light $(\sim 400-500 \mathrm{~nm})$. For any one phytochrome, there exists a photoequilibrium of two interconvertible forms, red and FR absorbing forms (also known as Pr and Pfr, respectively). Pfr is the active form of phytochrome and it elicits physiological responses (Shinomura et al., 2000). $\mathrm{Pr}$, the other form of phytochrome, is the inactive form that switches to Pfr upon absorbing 650-670 nm light (Nagatani, 2010; Folta and Carvalho, 2015). In long day plants, various experiments suggest that flowering is promoted mostly when red light (or light creating a high $\mathrm{Pfr} / \mathrm{Pr}$ ratio) is delivered during the early part of the photoperiod and when FR light (or light creating a lower $\mathrm{Pfr} / \mathrm{Pr}$ ratio) is delivered toward the

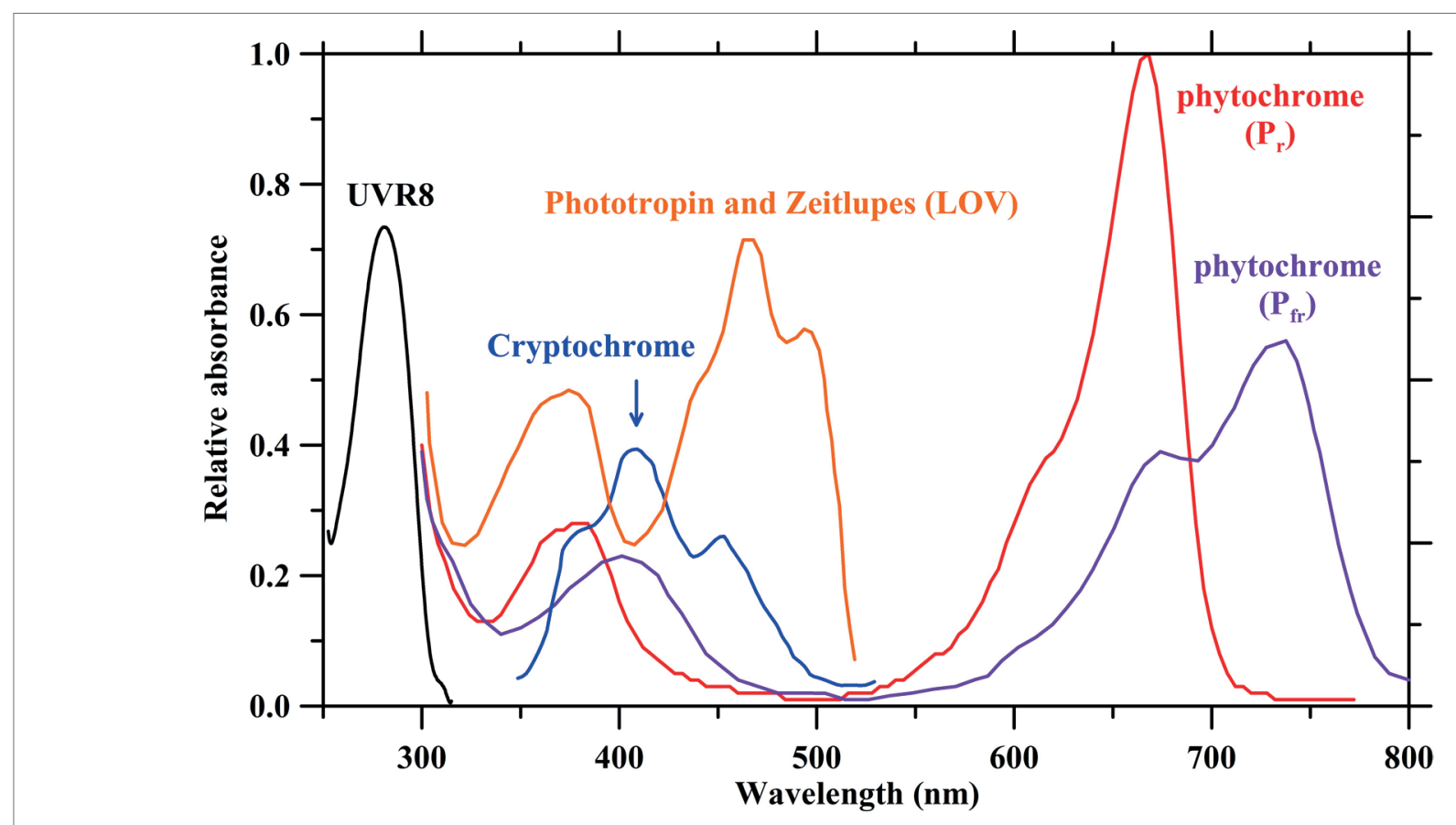

FIGURE 2 | Absorbance spectra of photoreceptors. Spectrum data are derived from Taiz and Zeiger (2002), Galvão and Fankhauser (2015), and Sager et al. (1988). 
end of the photoperiod (Lane et al., 1965; Evans, 1976; KadmanZahavi and Ephrat, 1976; Thomas and Vince-Prue, 1996). However, certain cannabis genotypes such as "G-170" are insensitive to changes in the R:FR ratio, and no effect on flowering has been observed (Magagnini et al., 2018). The authors concluded that a low R:FR ratio during a long photoperiod (18 $\mathrm{h}$ light, $6 \mathrm{~h}$ dark/vegetative stage) is beneficial to the development of mature cuttings, contradicting popular belief in the cannabis industry.

The effect of red light on plant physiology has been investigated (Poudel et al., 2008; Vu et al., 2014). Poudel et al. (2008) reported that red light induced an increase in rooting percentage and root numbers in grape (Vitis vinifera) plants. Wu and Lin (2012) showed that king protea (Protea cynaroides L.) plantlets grown in red light produce a higher number of roots and new leaves. Vu et al. (2014) reported that "Lapito" tomato plants grown solely under red LED light produce a higher total root surface area, length, and number of root tips in comparison with other light treatments. Lower leaf nitrogen content was found in rice (Oryza sativa L.) and spinach (Spinacia oleracea L., cv. Megaton) grown under red light treatment (Matsuda et al., 2004; Ohashi et al., 2005; Matsuda et al., 2007). In addition, photosynthetic rate reductions observed for plants grown under red light are reportedly due to stomata being controlled more by blue light than by red light (Sharkey and Raschke, 1981; Zeiger, 1984; Bukhov et al., 1996).

Red light further regulates flowering quality, quantity, and flowering duration (Bula et al., 1991; Tennessen et al., 1994). According to Guo et al. (1998) and Thomas and Vince-Prue (1996), inhibition of flowering with red light is effected by red light receptors including phytochromes (Kelly and Lagarias, 1985). The number of visible flower buds in marigold plants was approximately five times higher when grown with fluorescent light supplemented with red LEDs, as well as under fluorescent light, when compared to monochromatic blue or red light. No flower buds formed in salvia plants when grown under monochromic blue or red light or when fluorescent light supplemented with FR light was used for marigold (Tagetes minuta) plants.

Plants grown under canopy shade conditions or in the proximity of other plants show a range of responses to changes in R:FR ratios of ambient light. This response, known as shade avoidance or the near neighbor detection response, is characterized by an acceleration of flowering time (i.e., becoming visible within the expanded floral bud) and rapid elongation of stems and leaves (Halliday et al., 1994; Smith, 1994). Kasperbauer (1988) determined that FR light reflected from neighboring seedlings increased the R:FR ratio plants received, inducing a density-dependent increase in stem length, chloroplast content, chlorophyll $a / b$ ratio, and $\mathrm{CO}_{2}$ fixation rate, along with decreased leaf thickness. In recent years, the effect of FR light (or a low R:FR ratio) has been intensively investigated in different plant species and development stages (Li and Kubota, 2009; Finlayson et al., 2010; Mickens et al., 2018; Park and Runkle, 2018). Supplemental FR treatments increased dry mass for many greenhouse crops during vegetative development (Hogewoning et al., 2012; Lee et al., 2016; Mickens et al., 2018; Park and
Runkle, 2018), but conflicting results on leaf area were reported. Hogewoning et al. (2012) reported no significant difference in leaf area for tomato (L. esculentum "Mecano") and cucumber (Cucumis sativus "Venice"), whereas an increase in leaf area was observed for lettuce, petunia (Petunia $\times$ hybrida), geranium (Pelargonium $\times$ hortorum), and coleus (Solenostemon scutellariodes) (Lee et al., 2016; Mickens et al., 2018; Park and Runkle, 2018). Such differences in leaf area responses among species are still unknown and need to be addressed. For an extensive examination of FR light, the reader is referred to a recent review (Demotes-Mainard et al., 2016).

\section{Blue ( 450-520 nm) and UV $(<400 \mathrm{~nm})$ Light}

Blue and UV-A light triggers cryptochrome $(320-500 \mathrm{~nm})$ and phototropin (phot1 and pho2; 320-500 nm) function (Jones, 2018). These two photoreceptors regulate various physiological and developmental processes including chloroplast relocation, germination, elongation, and stomatal opening, which impacts water transpiration and $\mathrm{CO}_{2}$ exchange (Cosgrove, 1981; Schwartz and Zeiger, 1984). Blue light mediates chlorophyll and chloroplast development, enzyme synthesis, and plant density, and regulates responses to biotic environmental stresses (Goins et al., 1997; Schuerger et al., 1997). Walters and Horton (1995) reported that blue light deficiency can impact the light saturation rate of photosynthesis and can change the $\mathrm{Chl} a / b$ ratio in Arabidopsis thaliana. Blue light causes thickness of the epidermis and palisade mesophyll cells in Betula pendula (Sæbø et al., 1995). Lee et al. (2014) concluded that shorter blue wavelengths $(<445 \mathrm{~nm})$ promote stem growth, plant height, and anthocyanin synthesis in green perilla (Perilla frutescens var. japonica Hara cv. Soim) plants. Cannabis plants grown under blue light with a short photoperiod (12 h light:12 h dark/flowering stage) improved cannabinoid content (Magagnini et al., 2018). This same study suggested that there is a synergy between UV-A and blue wavelengths that induces cannabigerol accumulation in cannabis flowers.

Blue light activates Zeitlupe (ZTL) family function, a group of proteins that plays a role in circadian clock regulation, wherein their light-dependent function allows modulation of internal timing signals (Kim et al., 2007). Accordingly, optimal lighting regimes for cannabis growth and production should take advantage of this temporal regulation initiated by the circadian clock and light-sensitive ZTL protein function.

Wavelengths of light that are shorter than the PAR spectrum [e.g., violet light and UV $(<400 \mathrm{~nm})$ radiation] have limited photosynthesis; however, discrete photomorphogenic effects are observed when UV-B (290-320 nm) sensing systems are triggered (Frohnmeyer and Staiger, 2003; Folta and Carvalho, 2015). UV-B radiation is perceived via the UV-B photoreceptor UV resistance locus 8 (UVR8). Although UV-B represents a threat to plant integrity in large quantities, smaller quantities of UV-B have important benefits such as promoting pest resistance, increasing flavonoid accumulation, improving photosynthetic efficiency, and serving as an indicator of direct sunlight and sunflecks (Ballaré et al., 2012; Wargent and Jordan, 2013; Zoratti et al., 2014; Moriconi et al., 2018). Further to this, some UV-B responses can 
also be modulated by a UVR8-independent signal and UV-A radiation, since plants' responses to UV-B light are regulated by both UVR8-dependent and -independent pathways (Morales et al., 2013; Li et al., 2015; Jenkins, 2017). UV-B light reportedly elicits THC accumulation in both leaves and buds (Pate, 1983; Lydon et al., 1987; Potter and Duncombe, 2012).

\section{Green ( 520-560 nm) Light}

Green light is often considered unavailable for plant growth since plant photosynthetic pigments have limited absorbance for these wavelengths. However, there is evidence that green light is available for active plant growth, yet this phenomenon is wavelength- and intensity-dependent (Kim et al., 2004a; Kim et al., 2005; Johkan et al., 2012). Green light influences plant morphology, including leaf growth, stomatal conductance, and early stem elongation (Folta, 2004; Kim et al., 2004a,b). Kim et al. (2004) first examined the effect of green light on plant growth and photomorphogenesis, later concluding that it impacted plant growth at low light intensity $\left(\sim 150 \mu \mathrm{mol} \cdot \mathrm{m}^{-2} \cdot \mathrm{sec}^{-1}\right)$ (Kim et al., 2005). A low percentage $(\leq 24 \%)$ of green light enhanced plant growth, whereas plant growth was inhibited under a higher percentage of green light (Kim et al., 2004a, 2005; Folta and Maruhnich, 2007; Lee et al., 2011; Liu et al., 2017). Lee et al. (2011) reported that lady's slipper orchid grown under a combined LED lighting regime (8:1:1 ratio; $660 \mathrm{~nm}, 525 \mathrm{~nm}$, and $450 \mathrm{~nm})$ had at least $60 \%$ greater shoot dry mass when compared to blue or red LED emissions alone, or to a combination of red and blue lights at the same light intensity. Furthermore, green light exhibits better leaf tissue penetration ability (Brodersen and Vogelmann, 2010), resulting in better plant canopy penetration than either red or blue light (Klein, 1992). The issue with green light is that it exerts an antagonistic effect on other blue light-induced responses, including stomatal closure (Frechilla et al., 2000) or anthocyanin accumulation (Zhang and Folta, 2012). In cannabis plants, THC levels are negatively affected by the presence of green light (Mahlberg and Hemphill, 1983; Magagnini et al., 2018).

\section{Secondary Plant Metabolites}

Secondary plant metabolites such as carotenoids, flavonoids, and anthocyanins accumulate in plant cells and leaves as light-screening compounds to limit damage caused by high light intensity and UV radiation (Takahashi and Badger, 2011; Darko et al., 2014).

\section{Carotenoids}

Carotenoids are photosynthetic accessory pigments that have absorbance spectra in the $400-550 \mathrm{~nm}$ region (Frank and Cogdell, 1996). Carotenoids prevent photo-oxidative damage caused by the photosynthetic light harvesting apparatus and other cell components by thermally dissipating the excess energy of the single excited chlorophyll $\left({ }^{1} \mathrm{Chl}^{*}\right)$ and possibly a triplet excited chlorophyll $\left({ }^{3} \mathrm{Chl}^{\star}\right)$ within light reaction centers, as well as scavenging any evolved singlet-oxygen $\left({ }^{1} \mathrm{O}_{2}\right)$ (Müller et al., 2001; Mozzo et al., 2008).

\section{Terpenes}

Although present in much smaller quantities than cannabinoids, most terpenes in cannabis plants (e.g., monoterpenes and sesquiterpenes) are located in the glandular trichomes and are functionally diverse (Malingre et al., 1975; Turner et al., 1980). Terpenes are volatile aromatics that impact or contribute to the taste and smell of plants (Goff and Klee, 2006), defend against biotic stresses (Martin et al., 2003), and are plant hormones that regulate growth (Milborrow, 2001; Sakakibara, 2005; Hedden and Thomas, 2012). In addition, some terpenes help plants manage light and drought stress (Buchanan et al., 2000). Studies have demonstrated a relationship between terpene biosynthesis and light (Loveys and Wareing, 1971; Gleizes et al., 1980; Yamaura et al., 1991). Schnarrenberger and Mohr (1970) and Tanaka et al. (1989) both observed that carotenoid and monoterpene biosynthesis is regulated by the red light photoreceptor, phytochrome.

\section{Cannabinoids}

Cannabinoids are synthesized in secretory cells inside glandular trichomes, which are highly concentrated in unfertilized female flowers before senescence (Potter, 2004, 2009). Shoyama et al. (2008) found that cell death was induced when cannabis leaves secrete cannabinoids from glandular trichomes into leaf tissue. Lydon et al. (1987) reported increased THC concentrations when cannabis plants were grown with supplemental UV-B radiation, suggesting that cannabinoids may play some role in UV protection. Limited published research exists on the role of cannabinoids in cannabis plants.

\section{Flavonoids}

Flavonoids are sensitive to light quality, and flavonoid concentrations in plants are higher when grown under UV, blue, and FR light treatment (Fu et al., 2016; Pedroso et al., 2017; Liu et al., 2018). The two-ring, 15-carbon, general structure of flavonoids makes this group structurally and functionally diverse. Flavonoids comprise many classes (flavonols, flavones, flavanones, anthocyanins, and isoflavonoids) that are defined by various accessory groups attached to the central 15-carbon skeleton (Iwashina, 2000). This allows for their important roles as pollinator and feeding attractants, oviposition stimulants, and feeding deterrents, as well as in plant disease resistance and managing light stress (Hamamura et al., 1962; Ingham, 1972; Arakawa et al., 1985; Noh and Spalding, 1998; Nishida, 2005; Goff and Klee, 2006). Optimal lighting systems for cannabis growth and production must include an optimal light spectrum for flavonoid production. UV, blue, and FR are beneficial wavelengths that should be given greater consideration.

\section{ELECTRICAL LIGHTING SYSTEMS}

Electrical lighting systems usually serve as supplemental lighting for photoperiod control, to increase light intensity in a greenhouse, or as sole lighting for indoor plant production. Electrical lighting systems available for plant growth include incandescent bulbs, fluorescent bulbs, high pressure sodium (HPS) lamps, and LEDs. All of these light sources have been used throughout the history 
of cannabis production (Potter, 2009). For instance, fluorescent bulbs and HPS lamps are mainly used for young cuttings and during the flowering stage, respectively. For the vegetative growth stage, a wide variety of lighting types have been reported; these include metal halide bulbs, HPS lamps, LEDs, or a combination of different lighting types (Sweet, 2016; Chandra et al., 2017).

\section{Traditional Light Sources}

Sunlight and traditional light source spectra are shown in Figure 3. Incandescent light bulbs are composed of an airtight glass bulb and a tungsten filament that emanates electromagnetic radiation in the visible spectrum upon being heated (Kitsinelis, 2016). Visible light is emitted as the filament reaches $\sim 2,800 \mathrm{~K}$, with intensity increasing from 400 to $700 \mathrm{~nm}$ (Gupta and Agarwal, 2017). Most energy is emitted as FR light and only $60 \%$ of light energy is within the PAR spectrum. Its luminous efficiency never exceeds 20 lumens per watt $(\mathrm{lm} / \mathrm{W})$, and the energy conversion efficiency ranges from 1 to $5 \%$ (Gupta and Agarwal, 2017). The low luminous efficiency of incandescent light compared to other lighting systems has led to the phasing out of incandescent light bulbs, and they have limited applications for cannabis cultivation.

Gas discharge lamps include fluorescent bulbs, high-intensity discharge lamps, and metal halide lamps. Fluorescent bulbs are low-pressure mercury vapor discharge lamps that produce UV light via the ionization of the gaseous metal ions, which excite a phosphor coating that results in a visible light fluorescence. The energy conversion efficiency of fluorescent bulbs are below $30 \%$ (Shur and Zukauskas, 2005), yet the spectral quality of fluorescent bulbs has $90 \%$ of its emitted photons in the PAR spectrum (Gupta and Agarwal, 2017). The lifespan of fluorescent lamps, however, depends on starting and stopping frequencies since the emissive coating (usually phosphor) on the electrodes slowly evaporates during operation and rapidly erodes during start-up. Fluorescent bulbs are usually used for the establishment of seedlings or young cuttings of cannabis plants with an 18 -h photoperiod before transplanting (Chandra et al., 2017).

High-intensity discharge lamps operate under the same working principles as fluorescent bulbs, apart from being operated at high pressures and temperatures. High-intensity discharge lamps are classified into three types based on the vapors used: sodium, mercury, and metal halide. High-pressure mercury lamps have a luminous efficiency of $60 \mathrm{~lm} / \mathrm{W}$, whereas HPS lamps have a luminous efficiency between 80 and $125 \mathrm{~lm} / \mathrm{W}$. HPS lights not only emit most strongly in the yellow light $(560-600 \mathrm{~nm})$ of the PAR spectrum but also emit IR that is not useful for photosynthesis (Gupta and Agarwal, 2017). In both general horticultural and cannabis production industries, HPS lamps are widely used but have disadvantages. Firstly, high heat outputs $\left(>200^{\circ} \mathrm{C}\right)$ dramatically increase temperatures in the propagation room without proper thermal management.

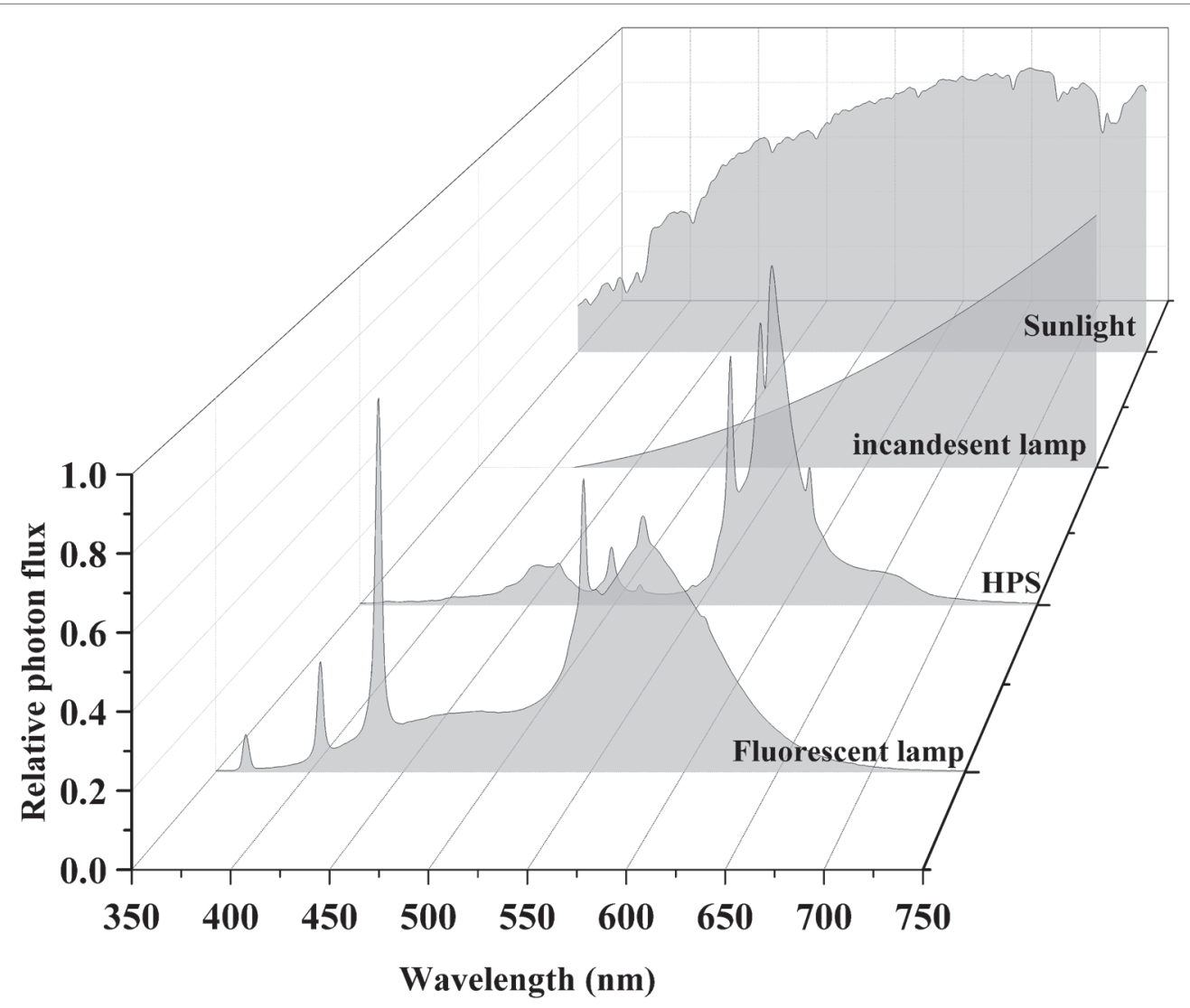

FIGURE 3 | Sunlight and traditional light source spectra. Data were collected using a spectroradiometer (PS-300, Apogee, UT). 
Secondly, although HPS lamps are rated for a longer lifespan $(24,000 \mathrm{~h})$ compared to fluorescent lamps, frequent starts will reduce the lifespan of HPS lamps, as does excessive lamp voltage (power surges). Metal halide lamps are modified high-pressure mercury vapor lamps. Spectral quality and intensity are controlled and have more visible wavelengths with the use of metal halides and mercury vapor. In addition, the spectral quality of the emitted radiation can be manipulated with the use of different metals and inert gases, producing light with a high luminous efficiency from 100 to $120 \mathrm{~lm} / \mathrm{W}$ (Gupta and Agarwal, 2017).

\section{Light Emitting Diodes}

LEDs are an emerging, versatile artificial light source offering many advantages over other conventional artificial light sources. Advantages include high photoelectric conversion efficiency $(\sim 50 \%)$, long lifespan $(30,000-50,000 \mathrm{~h})$, narrow spectral emissions $(\sim 10 \mathrm{~nm})$, and adjustable light intensity and quality to investigate the effects of many different spectral combinations of wavelengths on plant growth and development (Chang et al., 2012; Olle and Viršile, 2013). LED working principles and history have been extensively reviewed elsewhere (Morrow, 2008; Yeh and Chung, 2009; Singh et al., 2015; Cho et al., 2017; De Cesari et al., 2017; Viršile et al., 2017) and will not be repeated in this review. Typical LED spectra used in the general horticultural industry are shown in Figure 4.
Apart from versatility, LEDs can address the challenge of low light intensity within the plant canopy (Massa et al., 2005). In HPS and overhead LED lighting systems, the top of the canopy is often light saturated, while the whole canopy remains light-limited. Providing additional light to the lower canopy increases the proportion of light used for photosynthesis without exceeding the point of photosynthetic light saturation (Massa et al., 2005). Unlike HPS that dissipate heat toward the illuminated plane, LEDs dissipate their heat away from its illumination plane, thereby emitting little heat (Nelson and Bugbee, 2014). Producing significantly lower leaf temperatures, they can be used for closecanopy applications, making them a practical interlighting system in commercial settings. For example, a cowpea (Vigna unguicultata L. Walp.) canopy irradiated by intra-canopy LEDs improved biomass production, whereas plants grown under overhead lights produced less biomass and had a reduced energy conversion rate than plants grown with intra-canopy lights. When quantified, overhead-lighted plants averaged $75 \%$ the productivity of intracanopy-lighted plants (Massa et al., 2005).

\section{Spectral Effects on Cannabis Production}

Cannabis yield data often refers to dried floral material and corresponding cannabinoid content (Vanhove et al., 2011; Potter and Duncombe, 2012; Chandra et al., 2015). Dried bud yield may be presented on the basis of mass per plant (g per plant)

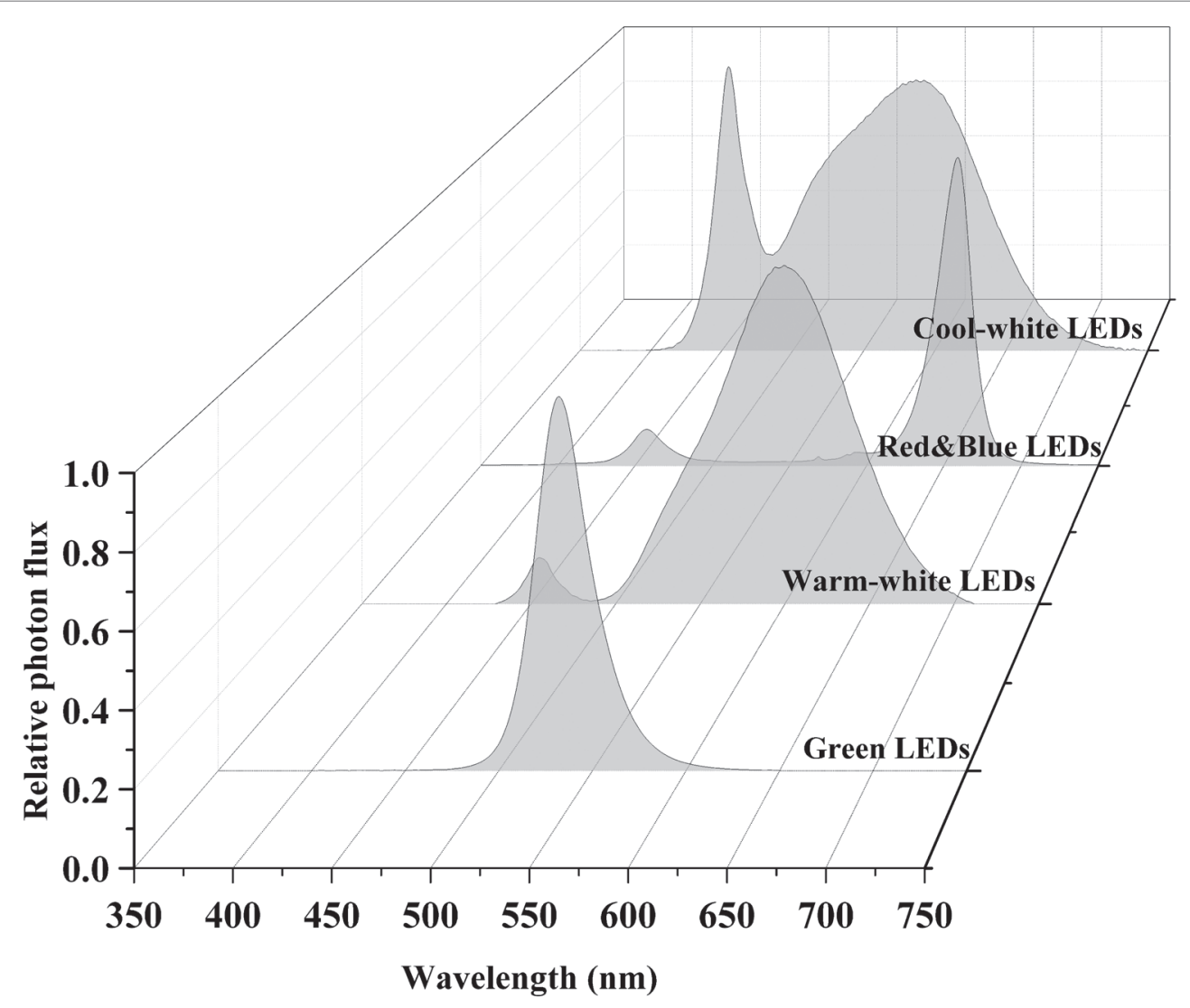

FIGURE 4 | Different LED light spectra. Data were collected using a spectroradiometer (PS-300, Apogee, UT). 
or mass per unit growing area $\left(\mathrm{g} \mathrm{m}^{-2}\right)$ (Table 1; Rosenthal, 2010; Potter and Duncombe, 2012; Vanhove et al., 2012). Currently, there is no "standard" unit to represent dried bud yield data. In recent years, unit mass per wattage of electrical energy consumed by the lighting system $\left(\mathrm{g} \mathrm{W}^{-1}\right)$, has been used, since it reflects the correlation between light intensity, cannabis growth, and lighting system efficacy (Hough, 2003; Potter and Duncombe, 2012). Depending on the cannabis plant variety, yield data in $g$ $\mathrm{W}^{-1}$ varies between $0.9-1.6 \mathrm{~g} \mathrm{~W}^{-1}$, and some growers claim that the "standard" unit is $1 \mathrm{~g} \mathrm{~W}^{-1}$ (Potter and Duncombe, 2012).

Cannabis plants have been cultivated under different lighting systems (Lydon et al., 1987; Chandra et al., 2008, 2015; Potter, 2009; Potter and Duncombe, 2012; Hawley, 2018; Magagnini et al., 2018). Lydon et al. (1987) and Marti et al. (2014) studied the effect of UV radiation on cannabis growth and cannabinoid profiles. Lydon et al. (1987) reported that supplementing with UV-B radiation for $3 \mathrm{~h}$ daily increased THC concentrations on C. sativa leaves and buds, whereas supplementing with UV-C radiation (100-280 nm) influenced resveratrol and piceid levels (Marti et al., 2014). Photosynthetic responses in C. sativa were measured at different light intensities, temperatures, and $\mathrm{CO}_{2}$ concentrations (Chandra et al., 2008, 2011a, 2015). Of the environmental conditions tested, the highest net photosynthetic rates occurred at $30^{\circ} \mathrm{C}$ and $1,500 \mu \mathrm{mol} \mathrm{m} \mathrm{m}^{-2} \mathrm{~s}^{-1}$, but this was reduced by nearly $20 \%$ when intensity increased to $2000 \mu \mathrm{mol} \mathrm{m} \mathrm{m}^{-2} \mathrm{~s}^{-1}$; no declined trend was observed at any other test temperatures (Chandra et al., 2008). At $25^{\circ} \mathrm{C}$, an increase in net photosynthetic rates with intensity was observed (Chandra et al., 2015). Further, elevated $\mathrm{CO}_{2}$ concentrations resulted in increased photosynthetic activity but had variety-specific responses (Chandra et al., 2011a).

Studies have reported that light spectrum influences cannabinoid quality and cannabinoid secondary metabolite production (Hawley, 2018; Magagnini et al., 2018). Magagnini et al. (2018) compared overhead HPS lamps to LEDs with two different light spectra (peaks at $\sim 450$ and $620 \mathrm{~nm}$, as well as at $\sim 450,550$, and $660 \mathrm{~nm}$ ). THC percentages in C. sativa $L$. flowers were 9.5 and $15.4 \%$ for LEDs and HPS, respectively, at $450 \mu \mathrm{mol} \mathrm{m} \mathrm{m}^{-2} \mathrm{~s}^{-1}$. Other cannabinoids such as CBD and cannabigerol showed higher concentrations under LED light treatments compared to HPS light. Hawley (2018) reported that combining 530-nm LED light, 440-nm LED light, 655-nm LED light, and metal halide lamps increased dry bud yield by $18-24 \%$ relative to the control. The same trends were observed with cannabinoid and terpene concentrations (Hawley, 2018). This up-regulation of secondary metabolites resulted in the up-regulation of IPP and DMAPP; both are precursors for terpenes and cannabinoids. In addition to environmental factors, studies reported that strain and plant density should be considered when estimating cannabis yield (Toonen et al., 2006; Vanhove et al., 2011; Potter and Duncombe, 2012; Vanhove et al., 2012).

Although beyond the scope of this review, it is still worth mentioning the importance of other environment conditions such as temperature, relative humidity, air circulation, fertilizer rate, substrate, $\mathrm{pH}$, and electrical conductivity (EC), all of which are critical for optimal cannabis growth. For cannabis plants, the ideal temperature is between 25 and $30^{\circ} \mathrm{C}$, yet this may vary depending on the genetic makeup and growth behavior of each plant strain (Chandra et al., 2008, 2011b). Recommended relative humidity levels are $75 \%$ during the development stage and $55-60 \%$ during the vegetative and flowering stages (Chandra et al., 2017); however, humidity as high as $90 \%$ has been reported for the propagation stage (Hawley, 2018; Magagnini et al., 2018). In the growing room, constant airflow and drier air are also recommended to prevent plant diseases and mold formation (Chandra et al., 2017). An optimized fertilizer rate of $351 \mathrm{mg}$ nitrogen per liter (N/L) for cannabis was achieved by supplying a range of nitrogen concentrations (117-585 $\mathrm{mg} \mathrm{N} / \mathrm{L}$ ) in a coir-based substrate with EC ranging between 0.9 and 3.9 $\mathrm{mS} \cdot \mathrm{cm}^{-1}$ and $\mathrm{pH}$ ranging between 6.74 and 7.16 (Caplan et al., 2017). A growing number of studies reporting optimal values

TABLE 1 | A comparison of cannabis yield data compiled from published reports (Vanhove et al., 2011; Potter and Duncombe, 2012; Vanhove et al., 2012; Caplan et al., 2017; Magagnini et al., 2018).

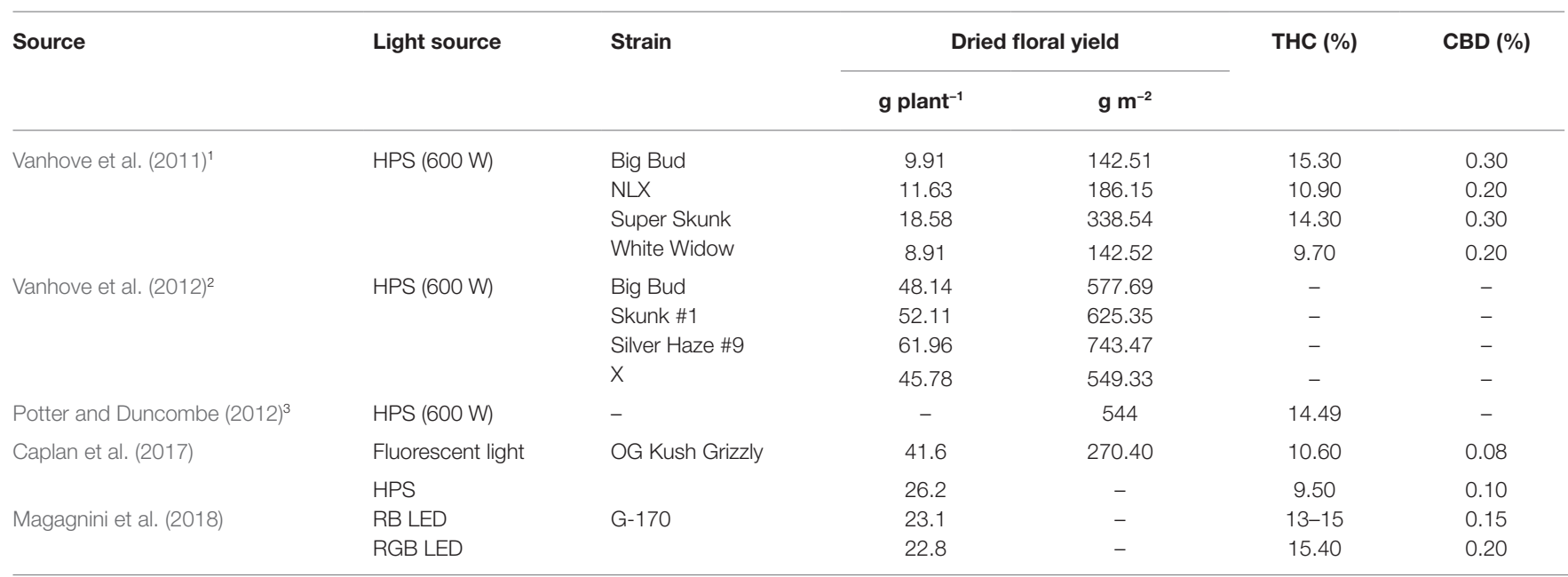

${ }^{1}$ Reported plant density of $16 \mathrm{~m}^{-2}$. ${ }^{2}$ Reported plant density of $12 \mathrm{~m}^{-2}$. ${ }^{3}$ Mean values for seven strains. 
for each of the aforementioned conditions for cannabis growth indicate that they have not yet been fully elucidated, particularly with respect to the individual cultivars.

\section{LEDs Versus HPS Lamps}

The ideal lighting system for cannabis growth is difficult to determine as both LEDs and HPS each have their respective advantages (Viršile et al., 2017). For large scale of production with uniformly spaced plants, HPS provides a broader uniform light distribution that can cover a larger area of production than LEDs (Nelson and Bugbee, 2014). However, LEDs can be optimized to specific production conditions by controlling periodicity, quantity, and spectrum of the light provided (Pinho et al., 2007). LEDs allow high-density production systems to have a focused spectral quality that can maximize radiation transfer to plants (Nelson and Bugbee, 2014). Their low heat emission allows them to be placed in the plant canopy for maximum cannabinoid yields (Viršile et al., 2017; Hawley, 2018).

Based on the cost analysis, photon efficacy, and capital costs of fixtures per photon delivered, it has been determined that LED fixtures cost five to ten times more than HPS fixtures, and that current, efficient fixtures available in the US have nearly identical efficiencies of 1.66-1.70 $\mu \mathrm{mol} \mathrm{J}^{-1}$ (Nelson and Bugbee, 2014). The same study showed that both technologies have relatively low long-term maintenance costs. Dutch and Danish LED fixtures with efficiencies of 2.2-2.4 $\mu \mathrm{mol} \mathrm{J}^{-1}$ are available in Europe, whereas the newest HPS lamps $(1,000 \mathrm{~W})$

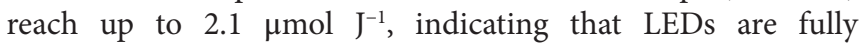
implementable on a commercial scale (Ouzounis et al., 2015).

\section{SUMMARY AND FUTURE PERSPECTIVES}

This review provides an outline of the impact of light on cannabis growth. Drawing on previous plant studies of other horticultural crops and using existing research performed on the cannabis plant, plant responses to different irradiance, wavelength, and photoperiods are summarized. The existing literature has demonstrated that both HPS and LEDs present viable lighting system options with possible benefits, but knowledge gaps remain with respect to cannabis production. To bridge these gaps, we propose several areas of focus for future experiments: (1)

\section{REFERENCES}

Arakawa, O., Hori, Y., and Ogata, R. (1985). Relative effectiveness and interaction of ultraviolet-B, red and blue light in anthocyanin synthesis of apple fruit. Physiol. Plant. 64, 323-327. doi: 10.1111/j.1399-3054.1985.tb03347.x

Arnold, J. M. (2013). Energy consumption and environmental impacts associated with cannabis cultivation. master's thesis. Arcata, CA: Humboldt State University.

Avital, S., Brumfeld, V., and Malkin, S. (2006). A micellar model system for the role of zeaxanthin in the non-photochemical quenching process of photosynthesis-chlorophyll fluorescence quenching by the xanthophylls. Biochim. Biophys. Acta Bioenerg. 1757, 798-810. doi: 10.1016/j.bbabio.2006.05.038

Ballaré, C. L., Mazza, C. A., Austin, A. T., and Pierik, R. (2012). Canopy light and plant health. Plant Physiol. 160, 145-155. doi: 10.1104/pp.112.200733 determine the effect of spectral quality on cannabis plant growth, particularly under high light intensities, as our current knowledge of spectral quality is based on typical greenhouse crops at moderate temperature $\left(20-25^{\circ} \mathrm{C}\right)$ and it is not yet known if we can apply the McCree PAR curve to cannabis plants; (2) determine the effect of environmental conditions such as temperature and humidity on different cannabis development stages, as current recommendations are ambiguous and mostly refer to vegetative and flowering stages; (3) determine the effect of light wavelength and intensity on photomorphogenesis (for each development stage) and final cannabis yield; (4) determine the effect of microclimate and different lighting systems on cannabis plant yield. For instance, investigating the effect of sole electrical lighting systems on indoor cannabis growth, and studying how airflow, temperature, and carbon dioxide might impact whole plant growth in these microclimates; (5) determine the effect of light on nutrient uptake in cannabis while examining substrate interactions and nutrient availability across different $\mathrm{EC}$ and $\mathrm{pH}$ ranges. In all, applied research will provide proven and reliable information that may ease cannabis plant production in this fast-paced and growing industry.

\section{AUTHOR CONTRIBUTIONS}

SB led the writing of this manuscript, edited it, and proofread it. B-SW contributed to writing the manuscript and provided the four figures. A-SR contributed to writing and was an active editor. SM contributed to the paper and was the major editor. ML contributed to writing the manuscript and is the correspondence author.

\section{FUNDING}

This was a review paper and all funding came from the NSERC Discovery Grant 355743-13.

\section{ACKNOWLEDGMENTS}

The authors thank McGill University for funding this work and all colleagues in the Biomass Production Laboratory for their continuous support.

Bantis, F., Smirnakou, S., Ouzounis, T., Koukounaras, A., Ntagkas, N., and Radoglou, K. (2018). Current status and recent achievements in the field of horticulture with the use of light-emitting diodes (LEDs). Sci. Hortic. 235, 437-451. doi: 10.1016/j.scienta.2018.02.058

Barnes, C., Tibbitts, T., Sager, J., Deitzer, G., Bubenheim, D., Koerner, G., et al. (1993). Accuracy of quantum sensors measuring yield photon flux and photosynthetic photon flux. HortSci. 28, 1197-1200. doi: 10.21273/ HORTSCI.28.12.1197

Benson, J. A. Jr., Watson, S. J. Jr., and Joy, J. E. (1999). Marijuana and medicine: Assessing the science base. Washington, DC: National Academies Press.

Blanchard, M. G., and Runkle, E. S. (2010). Intermittent light from a rotating high-pressure sodium lamp promotes flowering of long-day plants. HortSci. 45, 236-241. doi: 10.21273/HORTSCI.45.2.236 
Boese, S. R., and Huner, N. P. (1990). Effect of growth temperature and temperature shifts on spinach leaf morphology and photosynthesis. Plant Physiol. 94, 1830-1836. doi: 10.1104/pp.94.4.1830

Both, A.-J., Benjamin, L., Franklin, J., Holroyd, G., Incoll, L. D., Lefsrud, M. G., et al. (2015). Guidelines for measuring and reporting environmental parameters for experiments in greenhouses. Plant Methods 11:43. doi: 10.1186/ s13007-015-0083-5

Brodersen, C. R., and Vogelmann, T. C. (2010). Do changes in light direction affect absorption profiles in leaves? Funct. Plant Biol. 37, 403-412. doi: 10.1071/ FP09262

Buchanan, B. B., Gruissem, W., and Jones, R. L. (2000). Biochemistry \& molecular biology of plants. MD: American Society of Plant Physiologists Rockville.

Bugbee, B. (2016). "Toward an optimal spectral quality for plant growth and development: the importance of radiation capture" in VIII International Symposium on Light in Horticulture 1134. 1-12.

Bukhov, N., Bondar, V., Drozdova, I., Kara, A., Kotov, A., Maevskaya, S., et al. (1996). Development of storage roots in radish (Raphanus sativus) plants as affected by light quality. J. Plant Physiol. 149, 405-412. doi: 10.1016/ S0176-1617(96)80141-6

Bula, R., Morrow, R., Tibbitts, T., Barta, D., Ignatius, R., and Martin, T. (1991). Light-emitting diodes as a radiation source for plants. HortSci. 26, 203-205. doi: 10.21273/HORTSCI.26.2.203

Caplan, D., Dixon, M., and Zheng, Y. (2017). Optimal rate of organic fertilizer during the vegetative-stage for cannabis grown in two coir-based substrates. HortSci. 52, 1307-1312. doi: 10.21273/HORTSCI11903-17

Chandra, S., Lata, H., and Elsohly, M. A. (2017). Cannabis sativa L.- botany and biotechnology. Cham, Switzerland: Springer.

Chandra, S., Lata, H., Khan, I. A., and Elsohly, M. A. (2008). Photosynthetic response of Cannabis sativa $L$. to variations in photosynthetic photon flux densities, temperature and $\mathrm{CO}_{2}$ conditions. Physiol. Mol. Biol. Plants 14, 299-306. doi: 10.1007/s12298-008-0027-x

Chandra, S., Lata, H., Khan, I. A., and Elsohly, M. A. (2011a). Photosynthetic response of Cannabis sativa $L$., an important medicinal plant, to elevated levels of $\mathrm{CO}_{2}$. Physiol. Mol. Biol. Plants 17, 291-295. doi: 10.1007/ s12298-011-0066-6

Chandra, S., Lata, H., Khan, I. A., and Elsohly, M. A. (2011b). Temperature response of photosynthesis in different drug and fiber varieties of Cannabis sativa L. Physiol. Mol. Biol. Plants 17, 297. doi: 10.1007/s12298-011-0068-4

Chandra, S., Lata, H., Mehmedic, Z., Khan, I. A., and Elsohly, M. A. (2015). Light dependence of photosynthesis and water vapor exchange characteristics in different high $\Delta^{9}$-THC yielding varieties of Cannabis sativa L. J. Appl. Res. Med. Aromat. Plants 2, 39-47. doi: 10.1016/j.jarmap.2015.03.002

Chang, M.-H., Das, D., Varde, P., and Pecht, M. (2012). Light emitting diodes reliability review. Microelectron. Reliab. 52, 762-782. doi: 10.1016/j. microrel.2011.07.063

Cho, J., Park, J. H., Kim, J. K., and Schubert, E. F. (2017). White light-emitting diodes: history, progress, and future. Laser Photonics Rev. 11:1600147. doi: 10.1002/lpor.201600147

Clarke, R. C., and Merlin, M. D. (2013). Cannabis: Evolution and ethnobotany. Berkeley, CA: University of California Press.

Cooper, G. M., and Hausman, R. E. (2004). The cell: a molecular approach. Sunderland, MA: Sinauer Associates.

Cosgrove, D. J. (1981). Rapid suppression of growth by blue light occurrence, time course, and general characteristics. Plant Physiol. 67, 584-590. doi: 10.1104/ pp.67.3.584

Dahal, K., Kane, K., Gadapati, W., Webb, E., Savitch, L. V., Singh, J., et al. (2012). The effects of phenotypic plasticity on photosynthetic performance in winter rye, winter wheat and Brassica napus. Physiol. Plant. 144, 169-188. doi: 10.1111/j.1399-3054.2011.01513.x

Darko, E., Heydarizadeh, P., Schoefs, B., and Sabzalian, M. R. (2014). Photosynthesis under artificial light: the shift in primary and secondary metabolism. Philos. Trans. R. Soc. B 369:20130243. doi: 10.1098/rstb.2013.0243

De Cesari, S., Vitiello, E., Giorgioni, A., and Pezzoli, F. (2017). Progress towards spin-based light emission in group iv semiconductors. Electronics 6, 19. doi: 10.3390/electronics6010019

Demotes-Mainard, S., Péron, T., Corot, A., Bertheloot, J., Le Gourrierec, J., Pelleschi-Travier, S., et al. (2016). Plant responses to red and far-red lights, applications in horticulture. Environ. Exp. Bot. 121, 4-21. doi: 10.1016/j. envexpbot.2015.05.010
Dyer, O. (2018). Cannabis: Canada sees queues and shortages as it legalises recreational use. BMJ 363:k4421. doi: 10.1136/bmj.k4421

El-Alfy, A. T., Ivey, K., Robinson, K., Ahmed, S., Radwan, M., Slade, D., et al. (2010). Antidepressant-like effect of $\Delta^{9}$-tetrahydrocannabinol and other cannabinoids isolated from Cannabis sativa L. Pharmacol. Biochem. Behav. 95, 434-442. doi: 10.1016/j.pbb.2010.03.004

Erwin, J., and Gesick, E. (2017). Photosynthetic responses of Swiss chard, kale, and spinach cultivars to irradiance and carbon dioxide concentration. HortSci. 52, 706-712. doi: 10.21273/HORTSCI11799-17

Evans, L. (1976). Inflorescence initiation in Lolium temulentum L. XIV. The role of phytochrome in long day induction. Funct. Plant Biol. 3, 207-217. doi: 10.1071/PP9760207

Finlayson, S. A., Krishnareddy, S. R., Kebrom, T. H., and Casal, J. J. (2010). Phytochrome regulation of branching in Arabidopsis. Plant Physiol. 152, 1914-1927. doi: 10.1104/pp.109.148833

Fischedick, J. T., Hazekamp, A., Erkelens, T., Choi, Y. H., and Verpoorte, R. (2010). Metabolic fingerprinting of Cannabis sativa L., cannabinoids and terpenoids for chemotaxonomic and drug standardization purposes. Phytochemistry 71, 2058-2073. doi: 10.1016/j.phytochem.2010.10.001

Folta, K. M. (2004). Green light stimulates early stem elongation, antagonizing light-mediated growth inhibition. Plant Physiol. 135, 1407-1416. doi: 10.1104/ pp.104.038893

Folta, K. M., and Carvalho, S. D. (2015). Photoreceptors and control of horticultural plant traits. HortSci. 50, 1274-1280. doi: 10.21273/HORTSCI.50.9.1274

Folta, K. M., and Maruhnich, S. A. (2007). Green light: a signal to slow down or stop. J. Exp. Bot. 58, 3099-3111. doi: 10.1093/jxb/erm130

Frank, H. A., and Cogdell, R. J. (1996). Carotenoids in photosynthesis. Photochem. Photobiol. 63, 257-264. doi: 10.1111/j.1751-1097.1996.tb03022.x

Frechilla, S., Talbott, L. D., Bogomolni, R. A., and Zeiger, E. (2000). Reversal of blue light-stimulated stomatal opening by green light. Plant Cell Physiol. 41, 171-176. doi: 10.1093/pcp/41.2.171

Friedman, D., and Devinsky, O. (2015). Cannabinoids in the treatment of epilepsy. N. Engl. J. Med. 373, 1048-1058. doi: 10.1056/NEJMra1407304

Frohnmeyer, H., and Staiger, D. (2003). Ultraviolet-B radiation-mediated responses in plants. Balancing damage and protection. Plant Physiol. 133, 1420-1428. doi: $10.1104 /$ pp.103.030049

Fu, B., Ji, X., Zhao, M., He, F., Wang, X., Wang, Y., et al. (2016). The influence of light quality on the accumulation of flavonoids in tobacco (Nicotiana tabacum L.) leaves. J. Photochem. Photobiol. B Biol. 162, 544-549. doi: 10.1016/j.jphotobiol.2016.07.016

Galvão, V. C., and Fankhauser, C. (2015). Sensing the light environment in plants: photoreceptors and early signaling steps. Curr. Opin. Neurobiol. 34, 46-53. doi: 10.1016/j.conb.2015.01.013

Gleizes, M., Pauly, G., Bernard-Dagan, C., and Jacques, R. (1980). Effects of light on terpene hydrocarbon synthesis in Pinus pinaster. Physiol. Plant. 50, 16-20. doi: 10.1111/j.1399-3054.1980.tb02676.x

Goff, S. A., and Klee, H. J. (2006). Plant volatile compounds: sensory cues for health and nutritional value? Science 311, 815-819. doi: 10.1126/ science.1112614

Goins, G., Yorio, N., Sanwo, M., and Brown, C. (1997). Photomorphogenesis, photosynthesis, and seed yield of wheat plants grown under red light-emitting diodes (LEDs) with and without supplemental blue lighting. J. Exp. Bot. 48, 1407-1413. doi: $10.1093 / \mathrm{jxb} / 48.7 .1407$

Guo, H., Yang, H., Mockler, T. C., and Lin, C. (1998). Regulation of flowering time by Arabidopsis photoreceptors. Science 279, 1360-1363. doi: 10.1126/ science.279.5355.1360

Gupta, S. D., and Agarwal, A. (2017). "Artificial lighting system for plant growth and development: chronological advancement, working principles, and comparative assessment" in Light Emitting Diodes for Agriculture. ed. S. D. Gupta (Singapore: Springer), 1-25.

Hall, J., Bhattarai, S. P., and Midmore, D. J. (2014). The effects of photoperiod on phenological development and yields of industrial hemp. J. Nat. Fibers 11, 87-106. doi: 10.1080/15440478.2013.846840

Halliday, K. J., Koornneef, M., and Whitelam, G. C. (1994). Phytochrome B and at least one other phytochrome mediate the accelerated flowering response of Arabidopsis thaliana L. to low red/far-red ratio. Plant Physiol. 104, 1311-1315. doi: 10.1104/pp.104.4.1311

Hamamura, Y., Hayashiya, K., Naito, K.-I., Matsuura, K., and Nishida, J. (1962). Food selection by silkworm larvae. Nature 194, 754-755. doi: 10.1038/194754a0 
Hawley, D. (2018). The influence of spectral quality of light on plant secondary metabolism and photosynthetic acclimation to light quality. Ph.D. dissertation. Guelph, ON: University of Guelph.

Heber, U., and Shuvalov, V. A. (2005). Photochemical reactions of chlorophyll in dehydrated photosystem II: two chlorophyll forms (680 and $700 \mathrm{~nm}$ ). Photosynth. Res. 84, 85-91. doi: 10.1007/s11120-005-0413-y

Heddad, M., Norén, H., Reiser, V., Dunaeva, M., Andersson, B., and Adamska, I. (2006). Differential expression and localization of early light-induced proteins in Arabidopsis. Plant Physiol. 142, 75-87. doi: 10.1104/pp.106.081489

Hedden, P., and Thomas, S. G. (2012). Gibberellin biosynthesis and its regulation. Biochem. J. 444, 11-25. doi: 10.1042/BJ20120245

Hillig, K. W. (2005). Genetic evidence for speciation in Cannabis (Cannabaceae). Genet. Resour. Crop. Evol. 52, 161-180. doi: 10.1007/s10722-003-4452-y

Hoenecke, M., Bula, R., and Tibbitts, T. (1992). Importance of blue photon levels for lettuce seedlings grown under red-light-emitting diodes. HortSci. 27, 427-430. doi: 10.21273/HORTSCI.27.5.427

Hogewoning, S., Trouwborst, G., Meinen, E., and Van Ieperen, W. (2012). "Finding the optimal growth-light spectrum for greenhouse crops" in VII International Symposium on Light in Horticultural Systems 956. 357-363.

Hopkins, W. G., and Hüner, N. P. (1995). Introduction to plant physiology. New York: Wiley.

Hough, J. (2003). A growing market: The domestic cultivation of cannabis. York, UK: Joseph Rowntree Foundation.

Inada, K. (1976). Action spectra for photosynthesis in higher plants. Plant Cell Physiol. 17, 355-365.

Ingham, J. L. (1972). Phytoalexins and other natural products as factors in plant disease resistance. Bot. Rev. 38, 343-424. doi: 10.1007/BF02860009

Iwashina, T. (2000). The structure and distribution of the flavonoids in plants. J. Plant Res. 113, 287-299. doi: 10.1007/PL00013940

Jenkins, G. I. (2017). Photomorphogenic responses to ultraviolet-B light. Plant Cell Environ. 40, 2544-2557. doi: 10.1111/pce.12934

Johkan, M., Shoji, K., Goto, F., Hahida, S., and Yoshihara, T. (2012). Effect of green light wavelength and intensity on photomorphogenesis and photosynthesis in Lactuca sativa. Environ. Exp. Bot. 75, 128-133. doi: 10.1016/j. envexpbot.2011.08.010

Jones, M. A. (2018). Using light to improve commercial value. Horticul. Res. 5:47. doi: 10.1038/s41438-018-0049-7

Kadman-Zahavi, A., and Ephrat, E. (1976). Development of plants in filtered sunlight. III. Interaction of the spectral composition of main light periods with end of day red or far red irradiations and with red night interruptions in bolting and flowering of hyocyamus niger. Israel J. Bot. 25, 203-210

Kasperbauer, M. J. (1988). Phytochrome involvement in regulation of the photosynthetic apparatus and plant adaptation. Plant Physiol. Biochem. 26, 519-524.

Kelly, J. M., and Lagarias, J. C. (1985). Photochemistry of 124-kilodalton Avena phytochrome under constant illumination in vitro. Biochemistry 24, 6003-6010.

Kim, W.-Y., Fujiwara, S., Suh, S.-S., Kim, J., Kim, Y., Han, L., et al. (2007). ZEITLUPE is a circadian photoreceptor stabilized by GIGANTEA in blue light. Nature 449, 356. doi: 10.1038/nature06132

Kim, H.-H., Goins, G. D., Wheeler, R. M., and Sager, J. C. (2004a). Green-light supplementation for enhanced lettuce growth under red-and blue-light-emitting diodes. HortSci. 39, 1617-1622. doi: 10.21273/HORTSCI.39.7.1617

Kim, H.-H., Goins, G. D., Wheeler, R. M., and Sager, J. C. (2004b). Stomatal conductance of lettuce grown under or exposed to different light qualities. Ann. Bot. 94, 691-697. doi: 10.1093/aob/mch192

Kim, H.- H., Wheeler, R. M., Sager, J. C., Gains, G., and Naikane, J. (2005). "Evaluation of lettuce growth using supplemental green light with red and blue light-emitting diodes in a controlled environment-a review of research at Kennedy Space Center" in V International Symposium on Artificial Lighting in Horticulture 711. 111-120.

Kim, H. H., Wheeler, R. M., Sager, J. C., and Goins, G. D. (2004). Comparison of growth and photosynthetic characteristics of lettuce grown under red and blue light-emitting diodes (LEDS) with and without supplemental green LEDS. Acta Hortic. 659, 467-475. doi: 10.17660/ActaHortic.2004.659.62

Kitsinelis, S. (2016). Light sources: Technologies and applications. Boca Raton, FL: CRC Press.

Klein, R. M. (1992). Effects of green light on biological systems. Biol. Rev. 67, 199-284. doi: 10.1111/j.1469-185X.1992.tb01019.x
Kobayashi, M., Akutsu, S., Fujinuma, D., Furukawa, H., Komatsu, H., Hotota, Y., et al. (2013). "Physicochemical properties of chlorophylls in oxygenic photosynthesis-succession of co-factors from anoxygenic to oxygenic photosynthesis" in Photosynthesis. ed. Z. Dubinsky (London, UK: InTech), 47-90

Kohyama, F., Whitman, C., and Runkle, E. S. (2014). Comparing flowering responses of long-day plants under incandescent and two commercial lightemitting diode lamps. HortTechnology 24, 490-495. doi: 10.21273/ HORTTECH.24.4.490

Kołodziejek, J., and Patykowski, J. (2015). Effect of environmental factors on germination and emergence of invasive Rumex confertus in Central Europe. Sci. World J. 2015, 1-10 doi: 10.1155/2015/170176

Kriese, U., Schumann, E., Weber, W., Beyer, M., and Brühl, L. (2004). Oil content, tocopherol composition and fatty acid patterns of the seeds of 51 Cannabis sativa L. genotypes. Euphytica 137, 339-351. doi: 10.1023/B: EUPH.0000040473.23941.76

Lane, H., Cathey, H., and Evans, L. (1965). The dependence of flowering in several long-day plants on the spectral composition of light extending the photoperiod. Am. J. Bot. 52, 1006-1014. doi: 10.1002/j.1537-2197.1965. tb07278.x

Lee, Y., Fang, W., and Chen, C. (2011). "Effect of six different LED light qualities on the seedling growth of Paphiopedilum orchid in vitro" in:VI International Symposium on Light in Horticulture 907, 389-391.

Lee, J. S., Lee, C. A., Kim, Y. H., and Yun, S. J. (2014). Shorter wavelength blue light promotes growth of green perilla (Perilla frutescens). Int. J. Agric. Biol. 16, 1177-1182. ISSN 1814-9596 14-060/2014/16-6-1177-1182

Lee, M.-J., Son, K.-H., and Oh, M.-M. (2016). Increase in biomass and bioactive compounds in lettuce under various ratios of red to far-red LED light supplemented with blue LED light. Hortic. Environ. Biotechnol. 57, 139-147. doi: 10.1007/s13580-016-0133-6

Lefsrud, M. G., Kopsell, D. A., and Sams, C. E. (2008). Irradiance from distinct wavelength light-emitting diodes affect secondary metabolites in kale. HortSci. 43, 2243-2244. doi: 10.21273/HORTSCI.43.7.2243

Li, Q., and Kubota, C. (2009). Effects of supplemental light quality on growth and phytochemicals of baby leaf lettuce. Environ. Exp. Bot. 67, 59-64. doi: 10.1016/j.envexpbot.2009.06.011

Li, N., Teranishi, M., Yamaguchi, H., Matsushita, T., Watahiki, M. K., Tsuge, T., et al. (2015). UV-B-induced CPD photolyase gene expression is regulated by UVR8-dependent and-independent pathways in Arabidopsis. Plant Cell Physiol. 56, 2014-2023. doi: 10.1093/pcp/pcv121

Liu, Y., Fang, S., Yang, W., Shang, X., and Fu, X. (2018). Light quality affects flavonoid production and related gene expression in Cyclocarya paliurus. J. Photochem. Photobiol. B Biol. 179, 66-73. doi: 10.1016/j.jphotobiol.2018.01.002

Liu, H., Fu, Y., and Wang, M. (2017). Green light enhances growth, photosynthetic pigments and $\mathrm{CO}_{2}$ assimilation efficiency of lettuce as revealed by 'knock outof the 480-560 nm spectral waveband. Photosynthetica 55, 144-152. doi: 10.1007/s11099-016-0233-7

Loveys, B., and Wareing, P. (1971). The red light controlled production of gibberellin in etiolated wheat leaves. Planta 98, 109-116. doi: 10.1007/BF00385343

Lydon, J., Teramura, A. H., and Coffman, C. B. (1987). UV-B radiation effects on photosynthesis, growth and cannabinoid production of two Cannabis sativa chemotypes. Photochem. Photobiol. 46, 201-206. doi: 10.1111/j.1751-1097.1987. tb04757.x

Magagnini, G., Grassi, G., and Kotiranta, S. (2018). The effect of light spectrum on the morphology and cannabinoid content of Cannabis sativa L. Med. Cannabis Cannabinoids 1, 19-27. doi: 10.1159/000489030

Mahlberg, P. G., and Hemphill, J. K. (1983). Effect of light quality on cannabinoid content of Cannabis sativa L.(Cannabaceae). Bot. Gaz. 144, 43-48. doi: $10.1086 / 337342$

Malingre, T., Hendriks, H., Batterman, S., Bos, R., and Visser, J. (1975). The essential oil of Cannabis sativa. Planta Med. 28, 56-61. doi: 10.1055/s-0028-1097829

Marti, G., Schnee, S., Andrey, Y., Simoes-Pires, C., Carrupt, P.-A., Wolfender, J.-L., et al. (2014). Study of leaf metabolome modifications induced by UV-C radiations in representative Vitis, Cissus and Cannabis species by LC-MS based metabolomics and antioxidant assays. Molecules 19, 14004-14021. doi: 10.3390/molecules190914004

Martin, D. M., Gershenzon, J., and Bohlmann, J. (2003). Induction of volatile terpene biosynthesis and diurnal emission by methyl jasmonate in foliage of Norway spruce. Plant Physiol. 132, 1586-1599. doi: 10.1104/pp.103.021196 
Martineau, V., Lefsrud, M., Naznin, M. T., and Kopsell, D. A. (2012). Comparison of light-emitting diode and high-pressure sodium light treatments for hydroponics growth of Boston lettuce. HortSci. 47, 477-482. doi: 10.21273/HORTSCI.47.4.477

Massa, G. D., Emmerich, J. C., Mick, M. E., Kennedy, R., Morrow, R. C., and Mitchell, C. A. (2005). Development and testing of an efficient LED intracanopy lighting design for minimizing Equivalent System Mass in an advanced life-support system. Gravit. Space Bio Bull. 18, 87-88.

Massa, G. D., Kim, H.-H., Wheeler, R. M., and Mitchell, C. A. (2008). Plant productivity in response to LED lighting. HortSci. 43, 1951-1956. doi: 10.21273/HORTSCI.43.7.1951

Mathieu, J., Albright, J., and Leed, A. (2002). "A stand-alone light integral controller" in XXVI International Horticultural Congress: Protected Cultivation 2002: In Search of Structures, Systems and Plant Materials for 633. 153-159.

Matsuda, R., Ohashi-Kaneko, K., Fujiwara, K., Goto, E., and Kurata, K. (2004). Photosynthetic characteristics of rice leaves grown under red light with or without supplemental blue light. Plant Cell Physiol. 45, 1870-1874. doi: 10.1093/pcp/pch203

Matsuda, R., Ohashi-Kaneko, K., Fujiwara, K., and Kurata, K. (2007). Analysis of the relationship between blue-light photon flux density and the photosynthetic properties of spinach (Spinacia oleracea L.) leaves with regard to the acclimation of photosynthesis to growth irradiance. Soil Sci. Plant Nutr. 53, 459-465. doi: 10.1111/j.1747-0765.2007.00150.x

McCree, K. (1971). Significance of enhancement for calculations based on the action spectrum for photosynthesis. Plant Physiol. 49, 704-706.

McCree, K. (1972a). The action spectrum, absorptance and quantum yield of photosynthesis in crop plants. Agric. Meteorol. 9, 191-216.

McCree, K. (1972b). Test of current definitions of photosynthetically active radiation against leaf photosynthesis data. Agric. Meteorol. 10, 443-453.

McNellis, T. W., and Deng, X.-W. (1995). Light control of seedling morphogenetic pattern. Plant Cell 7, 1749. doi: 10.1105/tpc.7.11.1749

McPartland, J. M. (2017). "Cannabis sativa and Cannabis indica versus 'Sativa' and 'Indica"' in Cannabis sativa L.-botany and biotechnology eds. S. Chandra, H. Lata and M. A. Elsohly (Cham, Switzerland: Springer), 101-121.

Mercuri, A. M., Accorsi, C. A., and Mazzanti, M. B. (2002). The long history of Cannabis and its cultivation by the Romans in central Italy, shown by pollen records from Lago Albano and Lago di Nemi. Veg. Hist. Archaeobotany 11, 263-276. doi: 10.1007/s003340200039

Mickens, M., Skoog, E., Reese, L., Barnwell, P., Spencer, L., Massa, G., et al. (2018). A strategic approach for investigating light recipes for 'Outredgeous' red romaine lettuce using white and monochromatic LEDs. Life Sci. Space Res. 19, 53-62. doi: 10.1016/j.1ssr.2018.09.003

Milborrow, B. (2001). The pathway of biosynthesis of abscisic acid in vascular plants: a review of the present state of knowledge of ABA biosynthesis. J. Exp. Bot. 52, 1145-1164. doi: 10.1093/jexbot/52.359.1145

Mishra, S. R. (2004). Photosynthesis in plants. New Delhi, India: Discovery Publishing House.

Morales, L. O., Brosché, M., Vainonen, J., Jenkins, G. I., Wargent, J. J., Sipari, N., et al. (2013). Multiple roles for UV RESISTANCE LOCUS8 in regulating gene expression and metabolite accumulation in Arabidopsis under solar ultraviolet radiation. Plant Physiol. 161, 744-759. doi: 10.1104/pp.112.211375

Moriconi, V., Binkert, M., Rojas, M. C. C., Sellaro, R., Ulm, R., and Casal, J. J. (2018). Perception of sunflecks by the UV-B photoreceptor UV RESISTANCE LOCUS 8. Plant Physiol. 177, 75-81. doi: 10.1104/pp.18.00048

Morrow, R. C. (2008). LED lighting in horticulture. HortSci. 43, 1947-1950. doi: 10.21273/HORTSCI.43.7.1947

Mozzo, M., Dall'osto, L., Hienerwadel, R., Bassi, R., and Croce, R. (2008). Photoprotection in the antenna complexes of photosystem II: role of individual xanthophylls in chlorophyll triplet quenching. J. Biol. Chem. 283, 6184-6192. doi: 10.1074/jbc.M708961200

Müller, P., Li, X.-P., and Niyogi, K. K. (2001). Non-photochemical quenching. A response to excess light energy. Plant Physiol. 125, 1558-1566. doi: 10.1104/ pp. 125.4 .1558

Nagatani, A. (2010). Phytochrome: structural basis for its functions. Curr. Opin. Plant Biol. 13, 565-570. doi: 10.1016/j.pbi.2010.07.002

Naznin, M., Lefsrud, M., Gravel, V., and Hao, X. (2016). "Using different ratios of red and blue LEDs to improve the growth of strawberry plants" in VIII International Symposium on Light in Horticulture 1134. 125-130.

Nelson, J. A., and Bugbee, B. (2014). Economic analysis of greenhouse lighting: light emitting diodes vs. high intensity discharge fixtures. PLoS One 9:e99010. doi: $10.1093 /$ chemse/bjh230
Nishida, R. (2005). Chemosensory basis of host recognition in butterfliesmulti-component system of oviposition stimulants and deterrents. Chem. Senses 30, 293-294. doi: 10.1371/journal.pone.0099010

Noh, B., and Spalding, E. P. (1998). Anion channels and the stimulation of anthocyanin accumulation by blue light in Arabidopsis seedlings. Plant Physiol. 116, 503-509. doi: 10.1104/pp.116.2.503

Noodén, L. D., and Schneider, M. J. (2004). "Light control of senescence" in Plant cell death processes. ed. L. D. Noodén (Cambridge, MA: Academic Press), 375-383.

Ohashi, K., Goji, K., Matsuda, R., Fujiwara, K., and Kurata, K. (2005). "Effects of blue light supplementation to red light on nitrate reductase activity in leaves of rice seedlings" in V International Symposium on Artificial Lighting in Horticulture 711. 351-356.

Olle, M., and Viršile, A. (2013). The effects of light-emitting diode lighting on greenhouse plant growth and quality. Agric. Food Sci. 22, 223-234. doi: 10.23986/afsci.7897

Ouzounis, T., Heuvelink, E., Ji, Y., Schouten, H., Visser, R., and Marcelis, L. (2016). "Blue and red LED lighting effects on plant biomass, stomatal conductance, and metabolite content in nine tomato genotypes" in VIII International Symposium on Light in Horticulture 1134. 251-258.

Ouzounis, T., Razi Parjikolaei, B., Fretté, X., Rosenqvist, E., and Ottosen, C.-O. (2015). Predawn and high intensity application of supplemental blue light decreases the quantum yield of PSII and enhances the amount of phenolic acids, flavonoids, and pigments in Lactuca sativa. Front. Plant Sci. 6:19. doi: 10.3389/fpls.2015.00019

Park, I. S., Cho, K. J., Kim, J., Cho, J. Y., Lim, T. J., and Oh, W. (2016). Growth and flowering responses of petunia to various artificial light sources with different light qualities. Korean J. Hortic. Sci. Technol. 34, 55-66. doi: 10.12972/kjhst.20160016

Park, Y., and Runkle, E. S. (2018). Far-red radiation and photosynthetic photon flux density independently regulate seedling growth but interactively regulate flowering. Environ. Exp. Bot. 155, 206-216. doi: 10.1016/j.envexpbot.2018.06.033

Pate, D. W. (1983). Possible role of ultraviolet radiation in evolution of Cannabis chemotypes. Econ. Bot. 37, 396. doi: 10.1007/BF02904200

Pedroso, R. C. N., Branquinho, N.a. A., Hara, A. C., Costa, A. C., Silva, F. G., Pimenta, L. P., et al. (2017). Impact of light quality on flavonoid production and growth of Hyptis marrubioides seedlings cultivated in vitro. Rev. Bras 27, 466-470. doi: 10.1016/j.bjp.2016.12.004

Pinho, P., Lukalla, R., Sarkka, L., Tetri, E., Tahvonen, R., and Halonen, L. (2007). Evaluation of lettuce growth under multi-spectral-component supplemental solid state lighting in greenhouse environment. Int. Rev. Electr. Eng. 2, 854-860. ISBN 9789512295029

Pocock, T. (2015). Light-emitting diodes and the modulation of specialty crops: light sensing and signaling networks in plants. HortSci. 50, 1281-1284. doi: 10.21273/HORTSCI.50.9.1281

Potter, D. (2004). "Growth and morphology of medicinal cannabis" in The medicinal uses of Cannabis and cannabinoids. eds. G. Guy, B. A. Whittle and P. Robson (London: Pharmaceutical Press), 17-54.

Potter, D. (2009). The propagation, characterisation and optimisation of Cannabis sativa $\mathrm{L}$ as a phytopharmaceutical. Ph.D. dissertation. King's College London.

Potter, D. J., and Duncombe, P. (2012). The effect of electrical lighting power and irradiance on indoor-grown cannabis potency and yield. J. Forensic Sci. 57, 618-622. doi: 10.1111/j.1556-4029.2011.02024.x

Poudel, P. R., Kataoka, I., and Mochioka, R. (2008). Effect of red-and bluelight-emitting diodes on growth and morphogenesis of grapes. Plant Cell Tissue Organ Cult. 92, 147-153. doi: 10.1007/s11240-007-9317-1

Rosenthal, E. (2010). The big book of buds: More marijuana varieties from the world's great seed breeders. Oakland, CA: Quick Trading Co.

Ruhil, K., Ahmad, A., Iqbal, M., and Tripathy, B. C. (2015). Photosynthesis and growth responses of mustard (Brassica juncea L. cv Pusa Bold) plants to free air carbon dioxide enrichment (FACE). Protoplasma 252, 935-946. doi: 10.1007/s00709-014-0723-z

Sæbø, A., Krekling, T., and Appelgren, M. (1995). Light quality affects photosynthesis and leaf anatomy of birch plantlets in vitro. Plant Cell Tissue Organ Cult. 41, 177-185. doi: 10.1007/BF00051588

Sager, J., Edwards, J., and Klein, W. (1982). Light energy utilization efficiency for photosynthesis. Trans. ASAE 25, 1737-1746. doi: 10.13031/2013.33799

Sager, J. C., and Giger, W. Jr. (1980). Re-evaluation of published data on the relative photosynthetic efficiency of intermittent and continuous light. Agric. Meteorol. 22, 289-302. doi: 10.1016/0002-1571(80)90008-4 
Sager, J., Smith, W., Edwards, J., and Cyr, K. (1988). Photosynthetic efficiency and phytochrome photoequilibria determination using spectral data. Trans. ASAE 31, 1882-1889.

Sakakibara, H. (2005). Cytokinin biosynthesis and regulation. Vitam. Horm. 72, 271-287. doi: 10.1016/S0083-6729(05)72008-2

Schnarrenberger, C., and Mohr, H. (1970). Carotenoid synthesis in mustard seedlings as controlled by phytochrome and inhibitors. Planta 94, 296-307. doi: 10.1007/BF00385762

Schuerger, A. C., Brown, C. S., and Stryjewski, E. C. (1997). Anatomical features of pepper plants (Capsicum annuum L.) grown under red light-emitting diodes supplemented with blue or far-red light. Ann. Bot. 79, 273-282. doi: 10.1006/anbo.1996.0341

Schwartz, A., and Zeiger, E. (1984). Metabolic energy for stomatal opening. Roles of photophosphorylation and oxidative phosphorylation. Planta 161, 129-136. doi: 10.1007/BF00395472

Sharkey, T. D., and Raschke, K. (1981). Effect of light quality on stomatal opening in leaves of Xanthium strumarium L. Plant Physiol. 68, 1170-1174. doi: $10.1104 / p p .68 .5 .1170$

Shinomura, T., Uchida, K., and Furuya, M. (2000). Elementary processes of photoperception by phytochrome A for high-irradiance response of hypocotyl elongation in Arabidopsis. Plant Physiol. 122, 147-156. doi: 10.1104/ pp.122.1.147

Shoyama, Y., Sugawa, C., Tanaka, H., and Morimoto, S. (2008). Cannabinoids act as necrosis-inducing factors in Cannabis sativa. Plant Signal. Behav. 3, 1111-1112. doi: 10.4161/psb.3.12.7011

Shur, M. S., and Zukauskas, R. (2005). Solid-state lighting: toward superior illumination. Proc. IEEE 93, 1691-1703. doi: 10.1109/JPROC.2005.853537

Singh, D., Basu, C., Meinhardt-Wollweber, M., and Roth, B. (2015). LEDs for energy efficient greenhouse lighting. Renew. Sust. Energ. Rev. 49, 139-147. doi: $10.1016 /$ j.rser.2015.04.117

Smith, H. (1994). "Sensing the light environment: the functions of the phytochrome family" in Photomorphogenesis in plants. eds. R. E. Kendrick and G. H. Kronenberg (Dordrecht, The Netherlands: Kluwer Academic Publishers), $377-416$.

Stutte, G. W., Edney, S., and Skerritt, T. (2009). Photoregulation of bioprotectant content of red leaf lettuce with light-emitting diodes. HortSci. 44, 79-82. doi: 10.21273/HORTSCI.44.1.79

Sweet, S. L. (2016). The energy intensity of lighting used for the production of recreational cannabis in Washington State and implications for energy efficiency. Olympia, WA: Evergreen State College.

Taiz, L., and Zeiger, E. (2002). Plant Physiology. Sunderland, MA: Sinauer Associates Inc.

Takahashi, S., and Badger, M. R. (2011). Photoprotection in plants: a new light on photosystem II damage. Trends Plant Sci. 16, 53-60. doi: 10.1016/j. tplants.2010.10.001

Tanaka, S., Yamaura, T., Shigemoto, R., and Tabata, M. (1989). Phytochromemediated production of monoterpenes in thyme seedlings. Phytochemistry 28, 2955-2957. doi: 10.1016/0031-9422(89)80260-2

Tennessen, D. J., Singsaas, E. L., and Sharkey, T. D. (1994). Light-emitting diodes as a light source for photosynthesis research. Photosynth. Res. 39, 85-92. doi: 10.1007/BF00027146

Terashima, I., Fujita, T., Inoue, T., Chow, W. S., and Oguchi, R. (2009). Green light drives leaf photosynthesis more efficiently than red light in strong white light: revisiting the enigmatic question of why leaves are green. Plant Cell Physiol. 50, 684-697. doi: 10.1093/pcp/pcp034

Thomas, B., and Vince-Prue, D. (1996). Photoperiodism in plants. Cambridge, MA: Academic Press.

Toonen, M., Ribot, S., and Thissen, J. (2006). Yield of illicit indoor cannabis cultivation in the Netherlands. J. Forensic Sci. 51, 1050-1054. doi: 10.1111/j. 1556-4029.2006.00228.x

Turner, C. E., Elsohly, M. A., and Boeren, E. G. (1980). Constituents of Cannabis sativa L XVII. A review of the natural constituents. J. Nat. Prod. 43, 169-234. doi: $10.1021 / \mathrm{np} 50008 \mathrm{a} 001$

Van Ieperen, W., and Trouwborst, G. (2007). "The application of LEDs as assimilation light source in greenhouse horticulture: a simulation study" in International Symposium on High Technology for Greenhouse System Management: Greensys 2007 801. 1407-1414.
Van Iersel, M. W. (2017). "Optimizing LED lighting in controlled environment agriculture" in Light Emitting Diodes for Agriculture. ed. S. D. Gupta. (Singapore: Springer), 59-80.

Vanhove, W., Surmont, T., Van Damme, P., and De Ruyver, B. (2012). Yield and turnover of illicit indoor cannabis (Cannabis spp.) plantations in Belgium. Forensic Sci. Int. 220, 265-270. doi: 10.1016/j.forsciint.2012.03.013

Vanhove, W., Van Damme, P., and Meert, N. (2011). Factors determining yield and quality of illicit indoor cannabis (Cannabis spp.) production. Forensic Sci. Int. 212, 158-163. doi: 10.1016/j.forsciint.2011.06.006

Viršilè, A., Olle, M., and Duchovskis, P. (2017). "LED lighting in horticulture" in Light Emitting Diodes for Agriculture. ed. S.D. Gupta. (Singapore: Springer), $113-147$

Vu, N.-T., Kim, Y.-S., Kang, H.-M., and Kim, I.-S. (2014). Influence of shortterm irradiation during pre-and post-grafting period on the graft-take ratio and quality of tomato seedlings. Hortic. Environ. Biotechnol. 55, 27-35. doi: 10.1007/s13580-014-0115-5

Walters, R. G., and Horton, P. (1995). Acclimation of Arabidopsis thaliana to the light environment: regulation of chloroplast composition. Planta 197, 475-481. doi: 10.1007/BF00196669

Wang, J., Lu, W., Tong, Y., and Yang, Q. (2016). Leaf morphology, photosynthetic performance, chlorophyll fluorescence, stomatal development of lettuce (Lactuca sativa L.) exposed to different ratios of red light to blue light. Front. Plant Sci. 7:250. doi: 10.3389/fpls.2016.00250

Wargent, J. J., and Jordan, B. R. (2013). From ozone depletion to agriculture: understanding the role of UV radiation in sustainable crop production. New Phytol. 197, 1058-1076. doi: 10.1111/nph.12132

Warren, G. S. (2015). Regulating pot to save the polar bear: energy and climate impacts of the marijuana Industry. Columbia J. Environ. Law 40:385.

Wu, H.-C., and Lin, C.-C. (2012). Red light-emitting diode light irradiation improves root and leaf formation in difficult-to-propagate Protea cynaroides L. plantlets in vitro. HortSci. 47, 1490-1494. doi: 10.21273/HORTSCI.47.10.1490

Yamada, A., Tanigawa, T., Suyama, T., Matsuno, T., and Kunitake, T. (2008) Night break treatment using different light sources promotes or delays growth and flowering of Eustoma grandiflorum (Raf.) Shinn. J. Japan. Soc. Hortic. Sci. 77, 69-74. doi: 10.2503/jjshs1.77.69

Yamaura, T., Tanaka, S., and Tabata, M. (1991). Participation of phytochrome in the photoregulation of terpenoid synthesis in thyme seedlings. Plant Cell Physiol. 32, 603-607. doi: 10.1093/oxfordjournals.pcp.a078122

Yamori, W., Noguchi, K., and Terashima, I. (2005). Temperature acclimation of photosynthesis in spinach leaves: analyses of photosynthetic components and temperature dependencies of photosynthetic partial reactions. Plant Cell Environ. 28, 536-547. doi: 10.1111/j.1365-3040.2004.01299.x

Yeh, N., and Chung, J.-P. (2009). High-brightness LEDs-Energy efficient lighting sources and their potential in indoor plant cultivation. Renew. Sust. Energ. Rev. 13, 2175-2180. doi: 10.1016/j.rser.2009.01.027

Young, A. J. (1991). The photoprotective role of carotenoids in higher plants. Physiol. Plant. 83, 702-708. doi: 10.1111/j.1399-3054.1991.tb02490.x

Zeiger, E. (1984). "Blue light and stomatal function" in Blue light effects in biological systems ed. H. Senger. (Berlin, Heidelberg: Springer), 484-494.

Zelitch, I. (1975). Improving the efficiency of photosynthesis. Science 188, 626-633. doi: 10.1126/science.188.4188.626

Zhang, T., and Folta, K. M. (2012). Green light signaling and adaptive response. Plant Signal. Behav. 7, 75-78. doi: 10.4161/psb.7.1.18635

Zoratti, L., Karppinen, K., Luengo Escobar, A., Häggman, H., and Jaakola, L. (2014). Light-controlled flavonoid biosynthesis in fruits. Front. Plant Sci. 5:534. doi: 10.3389/fpls.2014.00534

Conflict of Interest Statement: The authors declare that the research was conducted in the absence of any commercial or financial relationships that could be construed as a potential conflict of interest.

Copyright (c) 2019 Eichhorn Bilodeau, Wu, Rufyikiri, MacPherson and Lefsrud. This is an open-access article distributed under the terms of the Creative Commons Attribution License (CC BY). The use, distribution or reproduction in other forums is permitted, provided the original author(s) and the copyright owner(s) are credited and that the original publication in this journal is cited, in accordance with accepted academic practice. No use, distribution or reproduction is permitted which does not comply with these terms. 